Eskişehir Osmangazi Üniversitesi ïBF Dergisi

Aralık 2017, C. 12, S.3, 15 - 36

Başvuru : 30.05 .2017

Kabul : :08.08.2017

\title{
Finansal Verilerin ARIMA ve ARCH Modelleriyle Öngörüsü: Türkiye Örneği
}

Nurdan Değirmenci ${ }^{1}$

Ali Akay ${ }^{2}$

Finansal Verilerin ARIMA ve ARCH Modelleriyle Öngörüsü: Türkiye Örneği

Öz

Bu çalışmanın amacı borsa, altın, döviz ve petrol fiyatlarının Box-Jenkins modelleri ve ARCH modelleri ile öngörülmesidir. Bu doğrultuda çalışmada BIST100 endeksi, altın ve petrol fiyatları ile döviz kuru değişkenlerine ait 01.02.2009-11.25.2016 tarihleri arasında yer alan haftalık veri setleri kullanılmıştır. Yapılan analizler sonucunda altın fiyatları haricindeki tüm değişkenlerde asimetrik etkinin varlığı ortaya koyulmuştur. Ayrıca ARCH modellerinden elde edilen öngörülerin theil istatistiklerinin sıfıra oldukça yakın olduğu bulunmuştur.

Anahtar Kelimeler: ARIMA, GARCH, EGARCH, Öngörü
Forecasting Financial Data with ARIMA and ARCH Models: The Case of Turkey

Abstract

The aim of this study is to predict the stock market, gold, foreign exchange and oil prices with Box-Jenkins and ARCH models. In this direction, weekly datasets are used of BIST100 index, gold and oil prices and exchange rate variables between 01.02.2009-11.25.2016. As a result of the analyses, asymmetric effect is revealed in all variables except gold prices. Also, the predictions obtained from the $\mathrm{ARCH}$ models were found to be close to zero in the theil statistics.

Keywords: ARIMA, GARCH, EGARCH, Forecast

\section{Giriş}

Hisse senedi, altın, döviz gibi yatırım araçlarında meydana gelen dalgalanmalar, başta ekonomistler olmak üzere yatırım kararı verecek olan herkesi yakından ilgilendirmektedir. Sürekli değişkenlik gösteren bu yatırım araçlarının tahmin edilmesi, gelecekte nasıl bir seyir izleyeceği hakkında bilgi sahibi olmak ya da öngörülerde bulunmak, özellikle yatırım sürecinde karar vericiler açıcından son derece önemli bir konudur.

Literatürde yatırım araçlarının gelecek değerlerini tahmin ederken, genellikle geleneksel Box-Jenkins yönteminin kullanıldığı görülmektedir. Bu yöntem, doğrusal zaman serilerinin analizinde sıkça kullanılan yöntemlerden birisidir. Box-Jenkins gibi geleneksel teknikler, geçmiş verilerden hareketle bir finansal varlığın davranışını ortaya koymaya çalışarak, bu yapının gelecekte de devam edeceği varsayımından hareketle öngörüde bulunurlar.

Çoğu zaman serisinde ele alınan dönem itibariyle ortalamanın sabit olmasına karşın, öngörülemeyen ani artış veya azalışlara bağlı olarak varyansın zaman içerisinde değiştiği gözlemlenmiştir. Bu durum geleneksel ekonometrik modellerin sabit varyanslılık varsayımını ihlal etmektedir. Özellikle finansal verilerin ele alındığı Box-jenkins yaklaşımıyla elde edilen modellerde, değişen varyans problemleri ile sıkça karşılaşılmaktadır. Bu sebeple Engle (1982), koşulsuz varyansın sabit olmakla birlikte koşullu varyansın geçmiş hataların bir fonksiyonu olarak değişmesine izin veren ARCH modellerini geliştirmiştir (Bollerslev,1986: 307). Son yıllarda finansal serilerin koşullu varyansındaki zamana bağı değişkenliği analiz etmek için ARCH modelleri de BoxJenkins modelleri ile birlikte yaygın olarak kullanılmaya başlanmıştır. Böylece finansal verilere

${ }^{1}$ Yrd. Doç. Dr., Recep Tayyip Erdoğan Üniversitesi, Fındıklı Uygulamalı Bilimler Yüksekokulu, Uluslararası Ticaret ve Lojistik Bölümü

${ }^{2}$ Yrd. Doç. Dr., Recep Tayyip Erdoğan Üniversitesi, Ardeşen Turizm Fakültesi, Turizm İşletmeciliği Bölümü 
ilişkin tahminlerde Box-Jenkins modellerini ARCH modelleri ile birleştirerek kullanmak daha sağlıklı sonuçlar ortaya koymaktadır.

ARCH modelinin uygulamasında, nispi olarak uzun gecikmeler kullanılması ve sabit gecikme yapısının önerilmesi nedeniyle, koşullu varyans denklemindeki parametrelere bazı kısıtlamalar konulmuştur. Bu kısıtlamaların sağlanamaması ve negatif varyanslı parametre tahminlerine ulaşılması sakıncasını gidermek amacıyla zaman içinde koşullu varyansın değişimi farklı modellerle açıklamaya çalışan ARCH türevi modeller geliştirilmiştir. Bollerslev (1986), Engle (1982)'ın ARCH modelini geliştirerek GARCH modelini önermiştir. GARCH modeli, hem otoregresif hem de hareketli ortalamalar terimlerinin koşullu varyansın modellenmesinde kullanılabilmesine imkân tanımaktadır. Bununla birlikte standart GARCH modelleri iyi ve kötü haberin oynaklık üzerinde neden olabileceği asimetrik etkiyi dikkate almamaktadır. Bu doğrultuda asimetrik etkinin araştırılması ve katsayı kısıtlarının minimize edilmesi amacıyla Nelson (1991) tarafından önerilen EGARCH modelleri kullanılmaktadır. EGARCH modeli, asimetrik etkiyi yani iyi ve kötü haberlerin varyans üzerinde simetrik etkiye sahip olup olmadığını ortaya koymaktadır. Bu özelliği ile hem değişen varyans sorununu ortadan kaldırmak hem de verilerde gözlenebilen asimetrik etkinin belirlenebilmesi amacıyla geleneksel Box-Jenkins yöntemleri ile birlikte EGARCH modelleri de literatürde yaygın olarak kullanılmaktadır.

Bu çalışmanın temel amacı borsa, altın, döviz ve petrol fiyatlarının Box-Jenkins modelleri ve ARCH modeli ile öngörülmesidir. Veri seti olarak BIST100 endeksi, altın ve petrol fiyatları ile döviz kuru değişkenleri ele alınmıştır. Bu doğrultuda çalışma 3 bölümden oluşmaktadır. Çalışmanın birinci bölümünde ampirik literatür özetlenmiştir. İkinci bölümünde kullanılan veri seti ve ekonometrik yöntem tanıtılmıştır. Son bölümde ise analiz bulguları ve bulgulara ilişkin değerlendirmeler sunulmuştur.

\section{Literatür}

Çalışmada ele alınan değişkenler itibariyle literatürde incelenen çalışmalardan bazıları aşağıda verilmiştir.

Borsayı baz alarak tahmin yapan çalışmalardan biri Özalp ve Anagün (2001)'ne aittir. Özalp ve Anagün (2001), gıda sektöründe işlem gören ve iki hisse senedine ilişkin fiyat değerlerini 1996-2001 dönemleri için Dolar-Mark kuru, enflasyon oranları, BIST-100 endeksi, işlem adedi ve işlem hacmi değerleri gibi bir takım ekonomik göstergelere ek olarak aynı sektörde işlem gören Tuborg Bira, Pınar Süt, Pınar Et-Un, Pınar Su ve Maret hisse senetlerinin aynı döneme ilişkin fiyat değerlerini de derleyerek tahminde bulunmuştur. Çalışmada öncelikle, çoklu doğrusal regresyon, doğrusal olmayan regresyon, üstel düzeltme, Winter' in üstel düzeltme yöntemi ve ARIMA (Bütünleşik Otoregresif Hareketli Ortalamalar) modellerinin denendiği klasik tahminleme yöntemleri kullanılmıştır. Aynı çalışma, Taguchi yöntemleri ile belirlenen yapay sinir ağı kullanılarak da gerçekleştirilmiş ve sonuçlar karşılaştırılmıştır. Çevik (2002), BIST endeksinin modellenmesi amacıyla 1986-2002 dönemine ait aylık verilerle Box-Jenkins modellerinden ARMA yöntemini kullanarak tahmin yaptığı çalışmasında seriye en uygun modelin ARIMA $(1,2,1)$ modelinin olduğunu tespit etmiştir. Gökbulut vd. (2011), 1987-2009 yılları için günlük BIST100 hisse senedi endeksini Box Jenkins ve ARCH tipi volatilite modelleriyle (ARCH-GARCH-EGARCHTARCH-GARCHM) tahmin etmeye çalışmışlardır. Sonuç olarak BIST100 getiri serisinin leptekurtic olduğu, volatilite kümelenmesi ve kaldıraç etkisi gösterdiği, volatilite tahmini için ise en iyi modelin TARCH $(1,1)$ modeli olduğu bulunmuştur. Yayar ve Karaca (2011), endeks tahmini için gerçekleştirdiği çalışmada Box-Jenkins modeli ile BIST endeks yönünü 1997-2009 aylık kapanış 
verilerini kullanarak geleceğe dönük tahmin etmeye çalışmışlardır. Çalışmada, 156 aylık veri kullanılmış ve geleceğe dönük 6 aylık tahminde bulunulmuştur. Etuk vd (2012), Nijerya hisse senedi piyasasını 1987-2006 dönemi aylık verilerini kullanarak Box-Jenkins yaklaşımıyla modellemeye çalışmışlardır. Model seçiminde $\mathrm{R}^{2}$, Akaike ve Schwarz bilgi kriterini kullanmışlardır. Sonuç olarak en uygun modelin sırasıyla ARMA $(2,1)$ ve ARIMA $(2,1,3)$ olduğu görülmüştür. Aygören vd. (2012), BIST 100 endeksi ile altın fiyatları, faiz oranı, bankalar arası çift tarafıı işlem miktarı $(T L)$ ve USD günlük kapanış değerlerini kullanarak ARMA(p,q), Nümerik Arama Modelleri için Newton yöntemi ve YSA için ise Geri Yayılım Algoritması ile model tahmininde bulunmuşlardır. Tahmin edilen model sonuçlarına göre geleneksel zaman serileri ve Newton Nümerik Arama modelleri YSA tekniğine göre daha başarısız bir performans sergilediği belirlenmiştir. Tayyar ve Tekin (2013), BIST-100 endeksinin hareket yönünün tahmini amacıyla Destek Vektör Makineleri (DVM) yöntemini kullanmışlardır. Çalışmada DVM'lerin sınıflandırma başarısı Lojistik Regresyon (LR) yöntemi ile karşılaştırılmıştır. Çalışmada hisse senedi analizinde teknik analizin yararlandığı araçlardan biri olan teknik göstergelerden (indikatörler) yararlanılmıştır. Modellere dâhil edilen teknik göstergeler LR analizi ile incelenmiştir. LR analizi sonucunda anlamlı olan göstergeler bağımsız değişken olarak kullanılmıştır. Her veri seti için 4 model oluşturulmuş ve her model için farklı değerlendirme kriterleri uygulanarak yöntemlerin endeks hareket yönü tahmin performansları değerlendirilmiştir. Yapılan değerlendirmeler sonucunda DVM'nin oluşturulan 12 model içerisinde BIST-100 endeksi hareket yönünü en iyi tahmin ettiği modelin haftalık model 1 olduğu $(\% 70,0)$ belirlenmiştir. Sekreter ve Gürsoy (2014), 2006-2012 dönemi günlük veri seti ile BIST-100 hisse senedi piyasasını ARIMA ve GARCH modelleriyle tahmin etmeye çalışmışlardır ve ARIMA modelinin en iyi tahmin sonucunu verdiğini ortaya koymuşlardır. Dritsaki (2015), Yunanistan hisse senedi piyasası için 1999-2014 dönemi için günlük verileri kullanarak ARIMA modelleriyle tahmin etmeye çalışmıştır.

Altın fiyatlarının tahmin edilmesinde ise Khaemasunun (2009), Thai altın fiyatlarının tahmini için çoklu regresyon modeli ve ARIMA modelini kullanmıştır. ARIMA modeli için 2002-2008, çoklu regresyon modeli için 2005-2008 dönemini ele almıştır. Sonuçta altın fiyatlarının tahmininde kısa dönemde en iyi modelin ARIMA $(1,1,1)$ modeli olduğu bulgularına ulaşmıştır. Lineesh vd. (2010), GARCH modeli, Dalgacık Sinir Ağı modeli (WNN), Trend ve Eşik Otoregresif modeli (T-TAR) ve WNN ile Trend ve Eşikli Otoregresif modeli gibi dört farklı tekniği kullanarak altın fiyatlarını tahmin etmeye çalışmışlardır. Sonuçta altın fiyatlarının tahmininde büyük örneklerde Dalgacık Sinir Ağı modeli daha etkili iken, küçük örneklerde Wavelet Neural Network ile Trend ve Threshold Autoregressive modelinin daha etkili olduğu görülmüştür. Deveci (2013), 20052012 arasındaki dönem için TL para arzı (M2), TL/USD değeri, Türkiye endüstri üretimi, tüfe, dünya tüfe, brent petrol, BIST 100, Türkiye gösterge tahvil faizi ve kredi risk değerlerini kullanarak Türkiye'de altın ve gümüş spot fiyatlarını ARIMAX ve Probit modelleri ile analiz etmiştir. Sonuç olarak altın için en iyi sonucu $\operatorname{ARIMAX}(0,1,0)$ modelinin ortaya koyduğunu bulmuştur. Ping vd. (2013), Malezyada 2001-2012 dönemi için günlük altın fiyatlarını tahmin ederken ARIMA ve GARCH modelini kullanmışlardır. Khan (2013), çalışmasında altın fiyatı için bir öngörü modeli geliştirmek istemiştir. Bu doğrultuda 2003-2012 dönemi verilerini ARIMA modeliyle tahmin etmeye çalışmıştır. Benli ve Yıldız (2014), altın fiyatının belirlenmesi amacıyla basit üstel düzgünleştirme yöntemi, Holt'un doğrusal trend yöntemi, ARIMA modeli ve YSA'yı kullanmış ve modeller arasında karşılaştırma yapmıştır. Analizde 1996-2013 dönemi aylık ağırlıklı ortalama altın fiyatları kullanılmıştır. Analiz sonucunda ARIMA modeli YSA modelinden daha başarılı bulunurken, YSA modelinin basit üstel düzgünleştirme yöntemi ve Holt'un doğrusal trend yöntemine göre daha başarılı bir tahmin performansı gösterdiği ortaya koyulmuştur. Yüksel ve Akkoç 
(2016), çalışmalarında 2002-2013 dönemine ait altın fiyatlarını YSA ile öngörmek amacıyla, altın fiyatlarını etkileyebileceği düşünülen değişkenler olan gümüş fiyatları, brent petrol fiyatları, ABD doları/ EUR paritesi, EuroNext100 endeksi, Amerika Dow Jones endeksi, ABD bonosu faiz oranı ve $A B D$ tüfe endeksi değişkenlerini kullanarak modeller belirlemiştir. Belirlenen modeller doğrultusunda YSA'nın altın fiyatlarının tahmininde başarı ile kullanılabileceğini göstermişlerdir. Ali Asad vd. (2016), 2014-2015 dönemi günlük veri setini kullanarak altın fiyatlarını ARIMA modeliyle tahmin etmeye çalışmışlardır.

Döviz kurunu ele alarak yapılan tahmin çalışmalarından biri ise Bircan ve Karagöz (2003)'e aittir. Bircan ve Karagöz (2003), çalışmada Box Jenkins metoduyla 1991-2002 dönemini kapsayan aylık döviz kuru serisi için en uygun tahmin modeli tespit etmeye çalışmışlardır. Yapılan tahmin sonucunda döviz kuru serisi için en iyi model ARIMA $(2,1,1)$ olarak tespit edilmiştir. Modelin uygunluğu için $Q$ istatistiği hesaplanarak, tahmin hatalarının tesadüfî olarak dağıldığına ve modelin döviz kuru tahminine uygun olduğuna yüzde 5 anlam seviyesinde karar verilmiştir. Tambi (2005), çalışmasında özel çekme hakları, USD, İngiliz Sterlini (GBP), Euro ve Yen gibi farklı para birimleri cinsinden Hint Rupisi döviz kurunu 1992-2004 dönemi için ARIMA modelleriyle tahmin etmiştir. Çalışmanın sonucuna göre basit otoregresif modeller ya da hareketli ortalama modellerine göre ARIMA modelinin daha iyi sonuç verdiği belirlenmiştir. Kadılar vd. (2009), çaIışmada Türkiye TL/US dolar döviz kuru zaman serisindeki değişimin modellenmesinde YSA (YSA), Box-Jenkins ve ARCH yöntemleri kullanmıştır. Elde edilen sonuçlara göre, YSA yönteminin mevsimsel ARIMA ve ARCH gibi modellerden daha iyi öngörüler ürettiği ortaya koyulmuştur. Pacelli (2012), günlük döviz kurundaki değişimleri YSA, Box-Jenkins ve GARCH modelleri gibi farklı yöntemleri kullanarak incelemiştir. Gupta ve Kashyap (2015), Hindistanda 1999-2014 dönemi için döviz kurundaki değişimleri tahmin etmek için aylık verileri kullanarak ARIMA modeli ile ABD doları, Yen, Euro ve GBP döviz kurundaki dalgalanmaları tahmin etmeye çalışmışlardır. Tlegenova (2015) ise ABD Doları (USD), Euro (EUR) ve Singapur Doları (SGD) olarak üç para birimi karşısında Kazak tengesinin (USD/KZT, EUR/KZT ve SGD/KZT) değişimini 2006-2014 dönemi aylık verilerini kullanarak ARIMA modelleriyle tahmin etmiştir.

Ham petrol fiyatlarının tahmininde klasik zaman serileri ve son zamanlarda YSA sıklıkla kullanılmaktadır. Xie vd. (2006)'nin petrol fiyat tahmini için yaptıkları çalışmada DVM tabanlı yeni bir model önerilmiştir. Bu modeli ARIMA ve Geri Yayılımlı Sinir Ağı (BPNN) modelleri ile karşılaştırarak önerdikleri modelin daha iyi performans gösterdiğini belirtmişlerdir. Fernandez (2007), ham petrol ve doğal gaz fiyatlarını tahmin ettiği çalışmasında YSA, DVM ve ARIMA modellerini karşılaştırmıştır. 2-4 gün gibi kısa vadede ARIMA'nın, 10-20 gün gibi uzun vadeli tahminlerde ise diğer iki metodun daha iyi performans gösterdiğini, YSA ve DVM'nin lineer kombinasyonunun ise modellerin tek tek gösterdiği performanstan daha iyi olduğunu belirtmişlerdir. Kaynar vd. (2010), çalışmada ham petrol fiyatlarını tahmin etmek için ARIMA ile MLP (Çok Katmanlı ileri Beslemeli) ve RBF (Radyal Tabanlı Fonksiyon) yapay sinir ağlarını kullanmışlardır. YSA kullanılarak elde edilen tahmin sonuçları SARIMA ile elde edilen tahmin değerlerinden daha iyi performans sergilemiştir. Yaziz vd. (2011), 1986-2009 dönemi günlük ham petrol fiyatlarını kullanarak Box-Jenkins ve GARCH modelleriyle petrol fiyatlarını tahmin etmeye çalışmışlardır. Bulgular doğrultusunda en uygun tahmin modelinin $\mathrm{GARCH}(1,1)$ modeli olduğunu ortaya koymuşlardır. Akomolafe ve Danladi (2013), 1993-2012 dönemi için aylık ham petrol fiyatlarını kullanarak Box-Jenkins yöntemiyle ham petrol fiyatlarını modelleyerek tahminde bulunmuşlar ve en uygun modelin AR(2) modeli olduğunu ortaya koymuşlardır. Muibi (2015), 2000-2012 dönemi 
aylık veri seti ile Nijerya ham petrol fiyatlarını Box-Jenkins modeli ile tahmin etmişlerdir. Mensah (2015) ise 1994-2014 dönemi için aylık brent petrol fiyatlarını kullanarak ARIMA modelleriyle tahminde bulunmaya çalışmıştır.

\section{Tablo 1: Literatür Özeti}

\begin{tabular}{|c|c|c|c|}
\hline Yazar & Dönem & Veri & Yöntem \\
\hline Özalp ve Anagün (2001) & 1996-2001 (aylık) & $\begin{array}{l}\text { Hisse senedi en- } \\
\text { deksi }\end{array}$ & Box-Jenkins modeli, YSA \\
\hline Çevik (2002) & 1986-2002 (aylık) & $\begin{array}{l}\text { Hisse senedi en- } \\
\text { deksi }\end{array}$ & Box-Jenkins modeli \\
\hline Yayar ve Karaca (2011) & 1997-2009 (aylık) & $\begin{array}{l}\text { Hisse senedi en- } \\
\text { deksi }\end{array}$ & Box-Jenkins modeli \\
\hline Gökbulut vd. (2011) & 1987-2009 (günlük) & $\begin{array}{l}\text { Hisse senedi en- } \\
\text { deksi }\end{array}$ & $\begin{array}{l}\text { Box-Jenkins ve ARCH tipi mo- } \\
\text { deller }\end{array}$ \\
\hline Aygören vd. (2012) & 1995-2010 (günlük) & $\begin{array}{l}\text { Hisse senedi en- } \\
\text { deksi }\end{array}$ & Box-Jenkins, YSA \\
\hline Etuk vd. (2012) & 1987-2006 (aylık) & $\begin{array}{l}\text { Hisse senedi en- } \\
\text { deksi }\end{array}$ & Box-Jenkins modeli \\
\hline Tayyar ve Tekin (2013) & $\begin{array}{l}\text { 1995-2012 (haftalık, ay- } \\
\text { lık) }\end{array}$ & $\begin{array}{l}\text { Hisse senedi en- } \\
\text { deksi }\end{array}$ & DVM yöntemi, LR modeli \\
\hline $\begin{array}{l}\text { Sekreter ve Gürsoy } \\
\text { (2014) }\end{array}$ & 2006-2012 (günlük) & $\begin{array}{l}\text { Hisse senedi en- } \\
\text { deksi }\end{array}$ & Box-Jenkins ve GARCH modeli \\
\hline Khaemasunun (2009) & 2002-2008 (aylık) & Altın & $\begin{array}{l}\text { Box-Jenkins ve Çoklu Regres- } \\
\text { yon Modeli }\end{array}$ \\
\hline Lineesh vd. (2010) & 1995-2008 (aylık) & Altın & $\begin{array}{l}\text { GARCH modeli, WWN modeli, } \\
\text { T-TAR modeli, WWN ile T-TAR } \\
\text { modeli }\end{array}$ \\
\hline Khan (2013) & 2003-2012 (günlük) & Altın & Box-Jenkins modeli \\
\hline Ping vd. (2013) & 2001-2012 (günlük) & Altın & Box-Jenkins modeli \\
\hline Deveci (2013) & 2005-2012 (aylık) & Altın & Box-Jenkins ve Probit modeli \\
\hline Benli ve Yıldız (2014) & 1996-2013 (aylık) & Altın & Box-Jenkins modeli \\
\hline Yüksel ve Akkoç (2016) & 2002-2013 (günlük) & Altın & YSA \\
\hline Ali Asad vd (2016) & 2014-2015 (günlük) & Altın & Box-Jenkins modeli \\
\hline $\begin{array}{l}\text { Bircan ve Karagöz } \\
(2003)\end{array}$ & 1991-2002 (aylık) & Döviz & Box-Jenkins modeli \\
\hline Tambi (2005) & 1992-2004 (aylık) & Döviz & Box-Jenkins modeli \\
\hline Kadılar vd. (2009) & 2005-2008 (haftalık) & Döviz & $\begin{array}{l}\text { YSA, Box-Jenkins ve ARCH } \\
\text { modelleri }\end{array}$ \\
\hline Pacelli (2012) & 1999-2009 (aylık) & Döviz & $\begin{array}{l}\text { YSA, Box-Jenkins ve GARCH } \\
\text { modelleri }\end{array}$ \\
\hline $\begin{array}{l}\text { Gupta ve Kashyap } \\
\text { (2015) }\end{array}$ & 1999-2014 (aylık) & Döviz & Box-Jenkins modeli \\
\hline Tlegenova (2015) & 2006-2014 (aylık) & Döviz & Box-Jenkins modeli \\
\hline Xie vd. (2006) & 1970-2003 (aylık) & Petrol & DVM, Box-Jenkins modeli \\
\hline Fernandez (2007) & 1994-2005 (günlük) & Petrol & $\begin{array}{l}\text { YSA, DVM, Box-Jenkins mo- } \\
\text { deli }\end{array}$ \\
\hline Kaynar vd. (2010) & 1986-2009 (aylık) & Petrol & Box-Jenkins ve YSA modeli \\
\hline Yaziz vd. (2011) & 1986-2009 (günlük) & Petrol & Box-Jenkins ve GARCH modeli \\
\hline $\begin{array}{l}\text { Akomolafe ve Danladi } \\
\text { (2013) }\end{array}$ & 1993-2012 (aylık) & Petrol & Box-Jenkins modeli \\
\hline Muibi (2015) & 2000-2012 (aylık) & Petrol & Box-Jenkins modeli \\
\hline Mensah (2015) & 1996-2012 (aylık) & Petrol & Box Jenkins modeli \\
\hline
\end{tabular}


Literatürdeki çalışmalar incelendiğinde, ekonomik değişkenlerin öngörüsünü yapmak için genellikle geleneksel zaman serisi yöntemlerinden olan Box-Jenkins yöntemi ve YSA'nın kullanıldığı belirlenmiştir. Bu yöntemler tek başına kullanılabildiği gibi performans karşılaştırması yapmak için de bir arada kullanılabilmektedir. Bu doğrultuda, yapılan çalışmalarda tahmin performanslarının karşılaştırılmasında bazı çalışmalar YSA yönteminin ARIMA ve ARCH gibi modellerden daha iyi öngörüler ürettiğini göstermektedir. Bazı çalışmalarda ise kısa vadede ARIMA'nın, uzun vadeli tahminlerde ise YSA'nın daha iyi performans gösterdiği belirtilmiştir.

\section{Veri ve Yöntem}

Bu çalışmada BIST100, altın ve petrol fiyatları ile döviz kuru değişkenleri geleneksel zaman serileri yöntemi olan Box-Jenkins ve ARCH modelleri ile öngörülmeye çalışılmıştır. Çalışmada 01.02.2009-11.25.2016 tarihleri arasında yer alan haftalık veri setleri kullanılmış ve tüm değişkenler logaritmik dönüşüme tabi tutulmuştur. Finansal zaman serilerindeki oynaklığın günlük veri seti ile çok daha açık bir biçimde ortaya konulabilmesi söz konusu olmakla birlikte günlük veri kullanımı analizlerde bazı problemler ortaya çıkarmaktadır. Günlük veri seti ile gerçekleştirilen analizlerde ARCH-GARCH modelleri tahmin edilirken özellikle ARIMA (Autoregressive Integrated Moving Average) modellerinin seçim aşamasında hata terimleri arasındaki otokorelasyon uygun modelin belirlenmesi aşamasında güçlüklere neden olmaktadır (Aggarwal vd., 1999: 36). Ayrıca bu çalışmada kullanılan değişkenlerin işlem günleri farklılık arz ettiğinden çalışma sonuçlarının karşılaştırılmasında bu farklılıkların etkisinin ortadan kaldırılması amaçlanmıştır. Bununla birlikte, çalışmada ele alınan değişkenlerin yatırım enstrümanı olması nedeniyle al-sat komisyonlarının ve değişkenlerin alım-satım fiyat farklarının yatırım getirisini olumsuz etkilemesi göz önüne alınarak günlük yerine haftalık veri seti kullanılması uygun görülmüştür. Uygulamada kullanılan veriler Yahoo. Finance ve Türkiye Cumhuriyeti Merkez Bankası Veri Dağıtım Sistemi'nden (TCMB-EVDS) günlük olarak elde edilerek haftalığa dönüştürülmüş ve Eviews 9 paket programı ile analiz edilmiştir. Tablo 2'de çalışmada ele alınan veri setine ilişkin bilgi sunulmuştur.

Tablo 2: Çalışmada Kullanılan Veriler

\begin{tabular}{ccc}
\hline Değişkenler & Veri Türü & Kaynak \\
\hline Altın & Haftalık & TCMB \\
\hline BIST100 & Haftalık & TCMB \\
\hline Brent Petrol & Haftalık & Yahoo Finance \\
\hline Döviz & Haftalık & TCMB \\
\hline
\end{tabular}

Çalışmada kullanılan her bir veri setine ilişkin getiri serileri $y_{t}=\left(p_{t}-p_{t-1}\right) * 100$ formülü yardımıyla hesaplanmıştır. Burada $p_{t}$, endeksin t dönemdeki kapanış fiyatını, $p_{t-1}$ ise $t-1$ dönemindeki kapanış fiyatını ifade etmektedir.

Zaman serilerinde ARIMA modellerinin belirlenip, öngörü yapılabilmesi ve ARCH modellerinin kullanılabilmesi için öncelikle ele alınan serilerin durağan oldukları seviyelerin belirlenmesi gerekmektedir. Bu amaçla çalışmada genişletilmiş Dickey-Fuller (ADF) ve Phillips-Perron (PP) birim kök testleri kullanılmıştır.

Dickey-Fuller (1979) yaklaşımında hata terimlerinin bağımsız ve aynı dağılıma sahip oldukları varsayımı geçerlidir. Phillips-Perron (1988) yaklaşımında ise hata terimlerinin zayıf bağımlı oldukları ve benzer dağılmadıkları kabul edilmektedir. ADF testi için (1) ve (2) numaralı denklemler kullanılmıştır ve denklemlerde bağımlı değişkenin gecikme uzunluklarının belirlenmesi için Akaike Bilgi Kriteri (AIC) dikkate alınmıştır. 


$$
\begin{aligned}
& \Delta y_{t}=\beta+\sum_{i=1}^{p} \phi_{i} \Delta y_{t-i}+\text { frend }+e_{t} \\
& \Delta y_{t}=\beta+\delta y_{t-1}+\sum_{i=1}^{p} \phi_{i} \Delta y_{t-i}+\text { ftrend }+e_{t}
\end{aligned}
$$

(1) ve (2) numaralı denklemlerde y, durağanlığı incelenen değişkeni; $\beta, \delta, \varphi$ ve $\gamma$, katsayıları; e, hata terimini ve $p$ ise optimal gecikme uzunluğunu ifade etmektedir. $\delta$ katsayısının $\mathrm{t}$ istatistiği MacKinnon tablo kritik değeriyle karşılaştırılarak serinin durağan olup olmadığı belirlenir. Eğer $t$ istatistiğinin mutlak değeri MacKinnon tablo kritik değerinin mutlak değerinden büyükse seri seviyesinde durağan kabul edilir.

PP testi için (3) ve (4) numaralı denklemler kullanılmıştır.

$$
\begin{aligned}
& \Delta y_{t}=\beta+\delta y_{t-1}+\mu_{t} \\
& \Delta y_{t}=\beta+\delta y_{t-1}+\gamma(\text { trend }-T / 2)+\mu_{t}
\end{aligned}
$$

(3) ve (4) numaralı denklemlerde y, durağanlığı incelenen değişkeni; $\beta, \delta$ ve $\gamma$, katsayıları; $\mu$, hata terimini; T ise gözlem sayısını ifade etmektedir. $\delta$ katsayısının t istatistiği Mackinnon tablo kritik değeriyle karşılaştırılarak serinin durağan olup olmadığına karar verilir.

Çalışmada, getiri serilerinin seviyesinde durağan olduğu tespit edildikten sonra, bütün seriler için uygun ARIMA modellerinin belirlenmesi amacıyla çeşitli ARIMA modelleri oluşturulmuştur. Uygun olan model katsayı anlamlılıkları Akaike bilgi kriteri (AIC) kullanılarak çok sayıda model arasından bir model seçilmiştir. Bunun yanı sıra modellerin otokorelasyon ve değişen varyans sorunu taşıyıp taşımadıkları da araştırılmıştır.

Doğrusal zaman serileri analizinde tahmin aşamasında en çok bilinen ve kullanılan yöntemlerden biri Box Jenkins yöntemi olarak da bilinen ARIMA modelidir. Bu yönteme göre, bağımlı değişken kendi gecikmiş değerleri ile rassal hata terimi tarafından açıklandığı varsayılmaktadır (Box ve Jenkins, 1976).

Box-Jenkins yöntemi dört aşamadan oluşmaktadır;

Belirleme: Zaman serisine uygun Box-Jenkins modeli belirlenir.

Parametre Tahmini: Belirlenen modele ilişkin parametreler tahmin edilir.

Tanı Koyma: Modelin, seriyi iyi açıklayıp açıklamadığını ortaya koymak için istatistiksel analizlerin yapılması aşamasıdır. Eğer kurulan model seriyi iyi açıklamıyorsa, yeniden başka bir model belirlenir.

Kestirim: Model seriyi iyi açıklıyorsa, ileriye yönelik tahmin aşamasına geçilir.

Bu aşamalardan sonra model tahmin amacıyla kullanılabilir. Bu yöntemde üç tür modelleme vardır. Bunlar, Otoregresif (AR) Süreç, Hareketli Ortalamalar (MA) Süreci ve Otoregresif Hareketli Ortalama (ARMA) Sürecidir.

ARIMA modelleri, durağan olmayan ancak fark alma işlemiyle durağan hale dönüştürülmüş serilere uygulanan modellerdir. Modellerin genel gösterimi ARIMA ( $p, d, q)$ şeklindedir. Burada $p$ ve q sırasıyla otoregresif (AR) modelin ve hareketli ortalama (MA) modelinin derecesini, $d$ ise fark alma derecesini göstermektedir. Genel $\operatorname{ARIMA}(p, d, q)$ modeli aşağıdaki eşitlik (5)'teki gibi ifade edilir.

$$
Z_{t}=\phi_{1} Z_{t-1}+\phi_{2} Z_{t-2}+\ldots .+\phi_{p} Z_{t-p}+\delta+a_{t}-\Theta_{1} a_{t-1}-\Theta_{2} a_{t-2}-\ldots-\Theta_{q} a_{t-q}
$$


Burada $Z_{t-1}, Z_{t-2}, \ldots, Z_{t-p}, d$. dereceden farkı alınmış gözlem değerlerini, $\phi_{1}, \phi_{2}, \ldots, \phi_{p} d$ dereceden farkı alınmış gözlem değerleri için katsayıları, $\delta$ sabit değeri, $a_{t}, a_{t-1}, \ldots, a_{t-q}$ hata terimlerini ve $\Theta_{1}, \Theta_{2}, \ldots, \Theta_{q}$ hata terimleri ile ilgili katsayıları göstermektedir.

ARIMA modellerinin seçiminden sonra hata terimlerinde $A R C H$ etkisi olup olmadığını test etmek amacıyla ARCH-LM (ARCH-Lagrange Multiple) testi kullanılmıştır. ARCH etkisi belirlendikten sonra getiri serilerindeki oynaklığın modellenmesinde kullanılacak GARCH ve EGARCH modelleri belirlenmiştir.

ARCH modelinin uygulamasında, nispi olarak uzun gecikmeler kullanılması ve sabit gecikme yapısının önerilmesi nedeniyle, koşullu varyans denklemindeki parametrelere bazı kısıtlamalar konulmuştur. Bu kısıtlamaların sağlanamaması ve negatif varyanslı parametre tahminlerine ulaşılması sakıncasını gidermek amacıyla, Bollerslev (1986), Engle (1982)'ın ARCH modelini geliştirerek GARCH modelini önermiştir. GARCH modeli, hem otoregresif hem de hareketli ortalamalar terimlerinin koşullu varyansın modellenmesinde kullanılabilmesine imkân tanımaktadır. Bununla birlikte standart GARCH modelleri iyi ve kötü haberin oynaklık üzerinde neden olabileceği asimetrik etkiyi dikkate almamaktadır. Bu doğrultuda kaldıraç etkisinin yani iyi ve kötü haberlerin varyans üzerinde simetrik etkiye sahip olup olmadığının belirlenmesi ve katsayı kısıtlarının minimize edilmesi amacıyla Nelson (1991) tarafından önerilen EGARCH modeli kullanılmıştır.

Nelson (1991)'ın geliştirdiği EGARCH $(1,1)$ modeli aşağıdaki (6) numaralı eşitlikteki gibidir.

$$
\log h_{t}=\alpha_{0}+\alpha_{1}\left(\frac{\varepsilon_{t-1}}{\sqrt{h_{t-1}}}\right)+\lambda_{1}\left|\frac{\varepsilon_{t-1}}{\sqrt{h_{t-1}}}\right|+\beta_{1} \log \left(h_{t-1}\right)
$$

Burada $\alpha$ parametresi asimetrik ARCH etkisini gösterir. Eğer $\alpha=0$ ise bir pozitif şok aynı büyüklükteki bir negatif şok ile aynı etkiye sahiptir. Eğer $0>\alpha>-1$ ise, bir negatif şok oynaklığı pozitif bir şoktan daha fazla arttırır ve böylece $\alpha$ oynaklık üzerindeki asimetrik şokları gösterir. Eğer $\alpha<-1$ ise, negatif (pozitif) şok genellikle oynaklığı arttırır (azaltır). Negatif ve istatistiksel olarak anlamlı $\alpha$ kaldıraç etkisinin varlığını gösterir. Gecikme uzunluklarının kesinliği, p ve q, alternatif özellikleri olan Likelihood Ratio (LR) testleri kullanılarak belirlenir. EGARCH modelinin belirlenmesinde $p$ ve $q$ gecikmeleri için tahmin edilen modellerin Ljung-Box ve LjungBox $^{2}$ istatistikleri dikkate alınmıştır. Bu model uygun $\operatorname{EGARCH}(p, q)$ modeline dayandırılarak test edilmiştir.

\section{Bulgular}

Çalışmada öncelikle getiri serilerine ilişkin tanımlayıcı istatistikler sunulmuştur. Tablo 3'te, BIST100, altın ve petrol fiyatları ile döviz kuru değişkenlerine ait ortalama getiri değerlerine bakıldığında bütün serilerin ortalama değerlerinin pozitif olduğu görülmektedir. En yüksek getirinin borsa, en düşük getirinin ise petrol değişkenine ait olduğu belirlenmiştir. Standart sapmalar karşılaştırıldığında en yüksek standart sapmaya petrol değişkeninin, en düşük standart sapmaya ise döviz değişkeninin sahip olduğu görülmektedir. Bu durum, petrol getiri serisinin ele alınan dönem boyunca diğer getiri serilerine kıyasla daha oynak bir yapı sergilediğini göstermektedir. Çarpıklık değerlerine bakıldığında altın, petrol ve borsa değişkenlerinin sola çarpık, döviz değişkeninin ise sağa çarpık olduğu anlaşılmaktadır. Basıklık değerlerine bakıldığında ise çoğu finansal zaman serilerinde karşılaşılan kalın kuyruk özelliği açıkça görülmektedir. 
Tablo 3: Getiri Serilerine Iliş̧kin Tanımlayıcı Istatistikler

\begin{tabular}{lcccc}
\hline & Altın & Borsa & Petrol & Döviz \\
\hline Ortalama & 0.000855 & 0.002459 & $1.75 \mathrm{E}-05$ & 0.001962 \\
\hline Medyan & 0.001774 & 0.004278 & 0.001749 & 0.001836 \\
\hline Max. & 0.067676 & 0.099647 & 0.131024 & 0.064258 \\
\hline Min. & -0.079193 & -0.143708 & -0.147812 & -0.059079 \\
\hline Std.Sapma & 0.022916 & 0.033875 & 0.042194 & 0.015345 \\
\hline Çarpıklık & -0.217334 & -0.521696 & -0.238350 & 0.210434 \\
\hline Basıklık & 3.479114 & 4.050165 & 3.997515 & 4.179142 \\
\hline JB & 0.027067 & 0.000000 & 0.000038 & 0.000001 \\
\hline
\end{tabular}

Çalışmada kullanılan değişkenlerin durağanlıkları araştırılırken ADF ve PP testlerinden yararlanılmıştır. Durağanlık analizi sonuçları Tablo 4'te sunulmuştur. Bu sonuçlara göre hem ADF hem de PP testine göre bütün seriler \%1 anlamlılık düzeyinde birim kök içermemektedir.

Tablo 4: Getiri Serilerine Ilişskin ADF ve PP Birim Kök Analizi

\begin{tabular}{lcccc}
\hline \multirow{2}{*}{ Değişkenler } & \multicolumn{2}{c}{ ADF } & Pabitli & Sabitli Trendli \\
\cline { 2 - 5 } & Sabitli & Sabitli Trendli & $-18.98063^{\mathrm{a}}$ & $-19.11785^{\mathrm{a}}$ \\
\hline Altın & $-19.01000^{\mathrm{a}}$ & $-19.15219^{\mathrm{a}}$ & $-21.18410^{\mathrm{a}}$ & $-21.37272^{\mathrm{a}}$ \\
\hline Borsa & $-21.20539^{\mathrm{a}}$ & $-21.37308^{\mathrm{a}}$ & $-19.01265^{\mathrm{a}}$ & $-19.22305^{\mathrm{a}}$ \\
\hline Petrol & $-19.00486^{\mathrm{a}}$ & $-19.22398^{\mathrm{a}}$ & $-19.27298^{\mathrm{a}}$ & $-19.35308^{\mathrm{a}}$ \\
\hline Döviz & $-19.27940^{\mathrm{a}}$ & $-19.37078^{\mathrm{a}}$ & -19 \\
\hline
\end{tabular}

a, \%1 seviyesinde serinin durağan olduğunu ifade etmektedir.

Getiri serilerinin seviyesinde durağan olduğu tespit edildikten sonra, bütün seriler için uygun ARIMA modellerinin belirlenmesi amacıyla Eviews program koduyla (Ek1) çeşitli ARIMA modelleri oluşturulmuş ve uygun olan model katsayı anlamlılıkları AIC bilgi kriterine göre çok sayıda model arasından seçilmiştir. ARIMA modelleri belirlendikten sonra modellerde ARCH etkisi araştırılmış ve sonuçlar Tablo 5 'te gösterilmiştir.

Tablo 5: Getiri Serilerine Ilişkin ARIMA Modelleri ve ARCH Etkisi

\begin{tabular}{lll}
\hline ARIMA Modelleri & AIC & ARCH Etkisi \\
\hline Altın-ARMA (2,4) & -4.711493 & $5.927783^{*}$ \\
\hline Borsa-ARMA (2,2) & -3.940013 & $2.801379 *$ \\
\hline Petrol-ARMA (3,2) & -3.483525 & $3.533120^{*}$ \\
\hline Döviz-ARMA (2,2) & -5.525018 & $1.896399^{*}$ \\
\hline * ilgili istatistiğin \%10 düzeyinde anlamlı olduğunu ifade etmektedir.
\end{tabular}

* ilgili istatistiğin \%10 düzeyinde anlamlı olduğunu ifade etmektedir.

Uygun ARIMA modellerindeki ARCH etkisinin varlığı tespit edildikten sonra, gereken değişkenler için ARCH-GARCH-EGARCH modellerinin belirlenmesi aşamasına geçilmiştir. ARCH modellerinin belirlenmesinde de ARIMA modellerinin belirlenmesinde kullanılan yönteme benzer şekilde Eviews program kodu kullanıımıştır (Ek2). Altın, borsa, petrol ve döviz getiri serileri için uygun olan modellerin tahmin sonuçları normal, t-student ve GED dağılımlarına göre tablo 6, tablo 7, tablo 8 ve tablo 9'da verilmiştir.

Tablo 6'da altın için normal, t-student ve GED dağılımlarına göre katsayıların istatistiksel anlamlılıkları, Log-Likelihood (LOGL) fonksiyonu, Ljung-Box (LB ${ }^{2}$ ) istatistikleri, Jarque-Bera (JB) ve $A R C H$ etkisi değerleri görülmektedir. Verilen modeller içerisinden max. LOGL değeri için en iyi model t-student dağılımına göre $\operatorname{AR}(2,4)-\mathrm{GARCH}(1,1)$ modelidir. Ayrıca, modellerden elde edilen standardize edilmiş hata terimlerinin karelerine ilişkin Ljung-Box $\left(\mathrm{LB}^{2}\right)$ istatistikleri de hata 
Eskişehir Osmangazi Üniversitesi IïBF Dergisi

terimleri arasında değişen varyans sorunu olmadığını ve hata terimlerinde ARCH etkisinin kalmadı̆̆ını da göstermektedir.

Tablo 6: Altın için ARCH-GARCH-EGARCH Modelleri

\begin{tabular}{|c|c|c|c|}
\hline Parametre & Normal & t-Student & GED \\
\hline \multicolumn{4}{|c|}{$\operatorname{AR}(2,4)-A R C H(1,0)$} \\
\hline$\omega$ & $0.0010^{\mathrm{a}}$ & $0.0010^{\mathrm{a}}$ & $0.0010^{a}$ \\
\hline$\alpha$ & $-0.9072^{b}$ & $-0.9164^{a}$ & $-0.9039^{b}$ \\
\hline LOGL & 979.2916 & 980.4962 & 980.0324 \\
\hline JB & $5.7860^{c}$ & $6.4050^{c}$ & $6.1472^{c}$ \\
\hline LB $^{2}(1)-A R C H(1)$ & $6.1370^{c}-6.1460^{b}$ & $5.9447^{c}-5.9506^{c}$ & $6.0182^{\mathrm{c}}-6.0254^{\mathrm{c}}$ \\
\hline LB $^{2}(5)-A R C H(5)$ & $16.2330^{\mathrm{b}}-2.8601^{\mathrm{b}}$ & $15.5550^{\mathrm{b}}-2.7782^{\mathrm{c}}$ & $15.8060^{b}-2.8060^{c}$ \\
\hline LB $^{2}(10)-A R C H(10)$ & $29.7940^{\mathrm{b}}-1.9528^{\mathrm{b}}$ & $28.9450^{\mathrm{b}}-1.9363^{\mathrm{c}}$ & $29.2450^{b}-1.9280^{c}$ \\
\hline $\mathrm{LB}^{2}(15)-\mathrm{ARCH}(15)$ & $36.5410^{\mathrm{b}}-1.6218^{\mathrm{c}}$ & $35.4050^{\mathrm{b}}-1.5925^{\mathrm{c}}$ & $35.8960^{b}-1.6009^{c}$ \\
\hline \multicolumn{4}{|c|}{$\operatorname{AR}(2,4)-\operatorname{EGARCH}(0,1,1)$} \\
\hline$\omega$ & -9.6253 & $-14.2895^{a}$ & -10.3460 \\
\hline$\alpha$ & -0.0382 & 0.0311 & -0.0203 \\
\hline$\theta$ & -0.2717 & $-0.8868^{a}$ & -0.3668 \\
\hline LOGL & 979.3429 & 980.9075 & 979.9452 \\
\hline JB & $4.8268^{c}$ & $6.8888^{c}$ & $5.5752^{c}$ \\
\hline LB $^{2}(1)-A R C H(1)$ & $5.8666^{c}-5.8677^{c}$ & $6.6595^{c}-6.6775^{c}$ & $5.8675^{c}-5.8724^{c}$ \\
\hline LB $^{2}(5)-A R C H(5)$ & $14.6710^{\mathrm{c}}-2.4524^{\mathrm{c}}$ & $16.3190^{\mathrm{b}}-2.8843^{\mathrm{c}}$ & $15.2230^{b}-2.6640^{c}$ \\
\hline $\mathrm{LB}^{2}(10)-\mathrm{ARCH}(10)$ & $28.5430^{\mathrm{b}}-1.9015^{\mathrm{c}}$ & $31.2960^{\mathrm{b}}-2.0844^{\mathrm{c}}$ & $27.6820^{b}-1.8268^{c}$ \\
\hline LB $^{2}(15)-A R C H(15)$ & $35.2990^{b}-1.5390^{c}$ & $38.7510^{\mathrm{b}}-1.7439^{\mathrm{c}}$ & $33.7450^{b}-1.5066^{c}$ \\
\hline \multicolumn{4}{|c|}{$\operatorname{AR}(2,4)-G A R C H(0,1)$} \\
\hline$\Omega$ & $0.0004^{\mathrm{a}}$ & $0.0004^{\mathrm{a}}$ & $0.0004^{\mathrm{a}}$ \\
\hline B & $0.1574^{c}$ & $0.1597^{c}$ & $0.1547^{c}$ \\
\hline LOGL & 982.6275 & 983.3195 & 982.8916 \\
\hline JB & $6.3416^{c}$ & $6.6038^{c}$ & $6.4725^{c}$ \\
\hline LB $^{2}(1)-A R C H(1)$ & $0.0232-0.0229$ & $0.0325-0.0321$ & $0.0154-0.0152$ \\
\hline LB $^{2}(5)-A R C H(5)$ & $6.8802-1.4312$ & $6.6814-1.3944$ & $6.7883-1.4126$ \\
\hline $\mathrm{LB}^{2}(10)-\mathrm{ARCH}(10)$ & $14.0200-1.2247$ & $13.6430-1.2018$ & $13.8560-1.2064$ \\
\hline $\mathrm{LB}^{2}(15)-\mathrm{ARCH}(15)$ & $19.4650-1.0893$ & $18.8550-1.0642$ & $19.2040-1.0743$ \\
\hline \multicolumn{4}{|c|}{$\operatorname{AR}(2,4)$-EGARCH $(1,0,1)$} \\
\hline$\omega$ & $-7.8266^{a}$ & $-7.8334^{a}$ & $-7.8246^{a}$ \\
\hline$\beta$ & $0.3026^{\mathrm{b}}$ & $0.3107^{c}$ & $0.3002^{c}$ \\
\hline$\theta$ & -0.0241 & -0.0073 & -0.0173 \\
\hline LOGL & 982.8882 & 983.5877 & 983.1309 \\
\hline JB & $6.2411^{c}$ & $6.8516^{c}$ & $6.4832^{c}$ \\
\hline LB $^{2}(1)-A R C H(1)$ & $0.0011-0.0011$ & $0.0093-0.0092$ & $0.0004-0.0004$ \\
\hline LB $^{2}(5)-A R C H(5)$ & $5.8166-1.1831$ & $5.7858-1.1865$ & $5.8155-1.1862$ \\
\hline $\mathrm{LB}^{2}(10)-\mathrm{ARCH}(10)$ & $13.0770-1.1333$ & $13.2360-1.1591$ & $13.1710-1.1372$ \\
\hline LB $^{2}(15)-A R C H(15)$ & $17.9710-1.0015$ & $18.0840-1.0181$ & $18.0370-1.0048$ \\
\hline \multicolumn{4}{|c|}{$\operatorname{AR}(2,4)-G A R C H(1,1)$} \\
\hline$\omega$ & 0.0001 & 0.0000 & 0.0001 \\
\hline$\alpha$ & 0.0668 & 0.0663 & 0.0655 \\
\hline$\beta$ & $0.8227^{\mathrm{a}}$ & $0.8424^{\mathrm{a}}$ & $0.8309^{a}$ \\
\hline LOGL & 985.4291 & 986.4409 & 985.693 \\
\hline JB & $8.5493^{c}$ & $9.6983^{b}$ & $8.8080^{c}$ \\
\hline LB $^{2}(1)-A R C H(1)$ & $0.2044-0.2016$ & $0.1807-0.1783$ & $0.2128-0.2099$ \\
\hline LB $^{2}(5)-A R C H(5)$ & $2.6473-0.4941$ & $2.5390-0.4777$ & $2.6001-0.4864$ \\
\hline $\mathrm{LB}^{2}(10)-\mathrm{ARCH}(10)$ & $7.4609-0.6938$ & 7.1131-0.6676 & $7.2721-0.6775$ \\
\hline LB $^{2}(15)-A R C H(15)$ & $11.2940-0.6782$ & $10.7980-0.6529$ & $11.0570-0.6656$ \\
\hline Parametre & Normal & t-Student & GED \\
\hline
\end{tabular}




\begin{tabular}{|c|c|c|c|}
\hline \multicolumn{4}{|c|}{$\operatorname{AR}(2,4)-E G A R C H(1,1,1)$} \\
\hline$\omega$ & -1.1205 & -0.9589 & -1.0566 \\
\hline$\alpha$ & 0.1521 & $0.1577^{c}$ & 0.1506 \\
\hline$\beta$ & 0.0087 & 0.0245 & 0.0137 \\
\hline$\theta$ & $0.8685^{a}$ & $0.8903^{a}$ & $0.8767^{a}$ \\
\hline LOGL & 984.6245 & 985.9346 & 984.9864 \\
\hline $\mathrm{JB}$ & $10.5748^{b}$ & $14.8375^{a}$ & $11.5753^{\mathrm{b}}$ \\
\hline $\mathrm{LB}^{2}(1)-A R C H(1)$ & $0.2600-0.2564$ & $0.1889-0.1863$ & $0.2546-0.2512$ \\
\hline $\mathrm{LB}^{2}(5)-A R C H(5)$ & $3.0589-0.5727$ & $3.0861-0.5812$ & $3.0637-0.5750$ \\
\hline LB $^{2}(10)-A R C H(10)$ & $10.1530-0.9392$ & $11.2660-1.0584$ & $10.3650-0.9625$ \\
\hline $\mathrm{LB}^{2}(15)-\mathrm{ARCH}(15)$ & $13.9930-0.8609$ & $14.6300-0.9276$ & $14.0520-0.8728$ \\
\hline
\end{tabular}

Borsa için verilen modeller içerisinden ise max. LOGL değeri için en iyi model t-student dağlımına göre AR(2,2)-EGARCH(1,1,1) modelidir (Tablo 7). EGARCH modeli asimetrik etkiyi dikkate almak amacıyla tercih edilmiştir. Sonuçlara göre asimetrik etkiyi gösteren $\theta$ parametresinin borsa getiri serisi için negatif ve istatistikî olarak \%1 düzeyinde anlamlı olduğu görülmektedir. Bu durum hisse senedi getirileri için asimetrik etkinin geçerli olduğunu göstermektedir. Asimetrik etki kötü haberin iyi habere göre hisse senedi getiri oynaklığını daha fazla arttırdığını ifade etmektedir. Ayrıca, modellerden elde edilen standardize edilmiş hata terimlerinin karelerine ilişkin $\mathrm{LB}^{2}$ istatistikleri de hata terimleri arasında değişen varyans sorunun ve hata terimlerinde $A R C H$ etkisinin kalmadığını da göstermektedir.

Tablo 7: BIST100 için ARCH-GARCH-EGARCH Modelleri

\begin{tabular}{|c|c|c|c|}
\hline Parametre & Normal & t-Student & GED \\
\hline \multicolumn{4}{|c|}{$\operatorname{AR}(2,2)-\operatorname{ARCH}(1,0)$} \\
\hline$\omega$ & 0.0000 & 0.0000 & 0.0004 \\
\hline$\alpha$ & $0.9842^{\mathrm{a}}$ & $0.9842^{\mathrm{a}}$ & 0.6214 \\
\hline LOGL & 817.4839 & 822.4774 & 817.3668 \\
\hline $\mathrm{JB}$ & $32.80712^{\mathrm{a}}$ & $39.71298^{a}$ & $36.43394^{a}$ \\
\hline $\mathrm{LB}^{2}(1)-\mathrm{ARCH}(1)$ & $2.9774^{c}-2.9556^{c}$ & $2.6066-2.5851$ & $1.9854-1.9666$ \\
\hline $\mathrm{LB}^{2}(5)-\mathrm{ARCH}(5)$ & $4.1284-0.8054(0.5463)$ & $3.6636-0.7053$ & $4.0104-0.8718$ \\
\hline LB $^{2}(10)-A R C H(10)$ & $5.6407-0.5329$ & 5.1224-0.4769 & $6.1688-0.6166$ \\
\hline $\mathrm{LB}^{2}(15)-\mathrm{ARCH}(15)$ & $18.7220-1.3655$ & $18.6620-1.3146$ & $15.6610-1.1109$ \\
\hline \multicolumn{4}{|c|}{$\operatorname{AR}(2,2)-\operatorname{EGARCH}(1,0,1)$} \\
\hline$\omega$ & -1.0853 & -1.2121 & -1.2999 \\
\hline$\alpha$ & -0.0329 & -0.0572 & -0.0602 \\
\hline$\theta$ & $0.8410^{\mathrm{a}}$ & $0.8228^{\mathrm{a}}$ & $0.8093^{\mathrm{a}}$ \\
\hline LOGL & 816.9753 & 822.501 & 818.1432 \\
\hline JB & $26.90878^{a}$ & $31.96725^{\mathrm{a}}$ & $26.09925^{a}$ \\
\hline LB'$^{2}(1)-A R C H(1)$ & 1.6113-1.5941 & $0.9661-0.9543$ & $0.9063-0.8953$ \\
\hline LB $^{2}(5)-A R C H(5)$ & $3.0894-0.6286$ & $2.5914-0.5231$ & $3.3500-0.7439$ \\
\hline LB $^{2}(10)-A R C H(10)$ & $4.5652-0.4378$ & $4.3760-0.4089$ & $5.9721-0.5827$ \\
\hline $\mathrm{LB}^{2}(15)-\mathrm{ARCH}(15)$ & $17.9570-1.2560$ & $18.3810-1.2077$ & $16.3340-1.0996$ \\
\hline \multicolumn{4}{|c|}{$\operatorname{AR}(2,2)-G A R C H(1,0)$} \\
\hline$\omega$ & $0.0010^{\mathrm{a}}$ & $0.0010^{\mathrm{a}}$ & $0.0010^{\mathrm{a}}$ \\
\hline$\beta$ & 0.0766 & 0.0627 & 0.0703 \\
\hline LOGL & 817.7719 & 822.4156 & 818.2576 \\
\hline JB & $32.80712^{\mathrm{a}}$ & $39.71298^{\mathrm{a}}$ & $36.43394^{a}$ \\
\hline LB'$^{2}(1)-A R C H(1)$ & 0.0141-0.0139 & $0.0266-0.0262$ & $0.0222-0.0219$ \\
\hline LB $^{2}(5)-A R C H(5)$ & $1.4798-0.2921$ & $1.6444-0.3212$ & $2.7218-0.5499$ \\
\hline $\mathrm{LB}^{2}(10)-\mathrm{ARCH}(10)$ & $2.8957-0.2609$ & $3.0014-0.2653$ & $4.8353-0.4378$ \\
\hline $\mathrm{LB}^{2}(15)-\mathrm{ARCH}(15)$ & $16.4290-1.0813$ & $16.3180-1.0228$ & $14.6120-0.9514$ \\
\hline Parametre & Normal & lent & GED \\
\hline
\end{tabular}




\begin{tabular}{|c|c|c|c|}
\hline \multicolumn{4}{|c|}{$\operatorname{AR}(2,2)-\operatorname{EGARCH}(0,1,1)$} \\
\hline$\omega$ & $-7.0019^{a}$ & $-6.9503^{a}$ & $-6.9808^{a}$ \\
\hline$\beta$ & $0.2225^{c}$ & 0.1704 & $0.2163^{c}$ \\
\hline$\theta$ & 0.0379 & -0.0106 & 0.0331 \\
\hline LOGL & 818.0664 & 822.0539 & 818.5566 \\
\hline JB & $40.54765^{a}$ & $46.73413^{a}$ & $49.17645^{a}$ \\
\hline LB $^{2}(1)-A R C H(1)$ & $0.0076-0.0075$ & $0.0349-0.0344$ & $0.0026-0.0025$ \\
\hline LB $^{2}(5)-A R C H(5)$ & $1.7964-0.3534$ & $1.5730-0.3075$ & $3.0169-0.6014$ \\
\hline $\mathrm{LB}^{2}(10)-\mathrm{ARCH}(10)$ & $3.3503-0.3012$ & $3.1737-0.2843$ & $5.1567-0.4698$ \\
\hline LB $^{2}(15)-A R C H(15)$ & $16.3490-1.0631$ & $16.5730-1.0431$ & $15.0780-0.9841$ \\
\hline \multicolumn{4}{|c|}{$\operatorname{AR}(2,2)-G A R C H(1,1)$} \\
\hline$\omega$ & $0.0021^{\mathrm{a}}$ & 0.0010 & $0.0021^{a}$ \\
\hline$\alpha$ & $0.0534^{c}$ & 0.0791 & $0.0535^{c}$ \\
\hline$\beta$ & $-0.9390^{a}$ & 0.0094 & $-0.9486^{a}$ \\
\hline LOGL & 820.8805 & 820.8656 & 821.4072 \\
\hline JB & $27.04447^{a}$ & $32.30391^{\mathrm{a}}$ & $26.03449^{a}$ \\
\hline LB $^{2}(1)-A R C H(1)$ & $0.3429-0.3382$ & $0.0957-0.0944$ & $0.4135-0.4081$ \\
\hline LB $^{2}(5)-A R C H(5)$ & $2.1402-0.4386$ & $1.7608-0.3707$ & $2.9776-0.6137$ \\
\hline LB $^{2}(10)-A R C H(10)$ & $3.7414-0.3546$ & $4.4575-0.4092$ & $5.6174-0.5382$ \\
\hline LB $^{2}(15)-A R C H(15)$ & $11.3170-0.6548$ & $12.2380-0.7955$ & $11.0570-0.5975$ \\
\hline \multicolumn{4}{|c|}{ AR(2,2)-EGARCH(1,1,1) } \\
\hline$\omega$ & $-12.4963^{a}$ & $-12.7702^{a}$ & $-12.3247^{a}$ \\
\hline$\alpha$ & $0.2229^{a}$ & $0.1709^{c}$ & $0.2578^{\mathrm{b}}$ \\
\hline$\beta$ & 0.0365 & 0.0196( & 0.0481 \\
\hline$\theta$ & $-0.7993^{a}$ & $-0.8465^{a}$ & $-0.7713^{a}$ \\
\hline LOGL & 821.9613 & $824.4372^{*}$ & 822.6662 \\
\hline JB & $17.02328^{a}$ & $20.64571^{a}$ & $11.84007^{\mathrm{b}}$ \\
\hline LB$^{2}(1)-A R C H(1)$ & $0.1259-0.1242$ & $0.3302-0.3256$ & $0.1409-0.1389$ \\
\hline LB $^{2}(5)-A R C H(5)$ & $1.5989-0.3247$ & $1.6282-0.3162$ & $1.8666-0.3879$ \\
\hline $\mathrm{LB}^{2}(10)-\mathrm{ARCH}(10)$ & $3.7648-0.3591$ & $3.7692-0.3492$ & $4.4329-0.4379$ \\
\hline LB $^{2}(15)-A R C H(15)$ & $12.0770-0.7254$ & $12.7010-0.7465$ & $11.5670-0.6668$ \\
\hline
\end{tabular}

Tablo 8'de petrol için verilen modeller incelendiğinde max. LOGL değeri için en iyi modelin t-student dağılımına göre $\operatorname{AR}(3,2)-\operatorname{EGARCH}(1,1,1)$ modeli olduğu görülmektedir. Asimetrik etki parametresinin $(\theta)$ döviz getiri serisi için pozitif ve istatistikî olarak \%1 düzeyinde anlamlı olduğu görülmektedir. Yani döviz getirileri için kötü haberin iyi habere göre döviz getiri oynaklığını daha fazla arttırdığı söylenebilir. Fakat modellerden elde edilen standardize edilmiş hata terimlerinin karelerine ilişkin $\mathrm{LB}^{2}$ istatistiklerine bakıldığında hata terimleri arasında değişen varyans sorununun ve $A R C H$ etkisinin tamamen giderilemediği görülmektedir.

Tablo 8: Petrol için ARCH-GARCH-EGARCH Modelleri

\begin{tabular}{|c|c|c|c|}
\hline Parametre & Normal & t-Student & GED \\
\hline \multicolumn{4}{|c|}{$\operatorname{AR}(3,2)-A R C H(1,0)$} \\
\hline$\omega$ & 0.0004 & 0.0006 & 0.0005 \\
\hline$\alpha$ & 0.7686 & 0.6302 & 0.6938 \\
\hline LOGL & 711.9143 & 720.1743 & 722.211 \\
\hline JB & $16.39043^{\mathrm{a}}$ & $34.28665^{a}$ & $33.67958^{a}$ \\
\hline LB $^{2}(1)-A R C H(1)$ & $9.1675^{b}-9.2538^{b}$ & $8.5367^{b}-8.6036^{b}$ & $8.3763^{b}-8.4394^{b}$ \\
\hline LB $^{2}(5)-A R C H(5)$ & $28.3880^{\mathrm{a}-4.1468^{\mathrm{b}}}$ & $28.3230^{\mathrm{a}}-4.1864^{\mathrm{b}}$ & $28.4450^{\mathrm{a}}-4.2338^{\mathrm{a}}$ \\
\hline LB $^{2}(10)-A R C H(10)$ & $64.4340^{\mathrm{a}}-3.6821^{\mathrm{a}}$ & $62.9460^{\mathrm{a}}-3.6252^{\mathrm{a}}$ & $62.4330^{\mathrm{a}}-3.6589^{\mathrm{a}}$ \\
\hline LB $^{2}(15)-A R C H(15)$ & $68.3400^{\mathrm{a}}-2.5010^{\mathrm{b}}$ & $65.6640^{\mathrm{a}}-2.4944^{\mathrm{b}}$ & $65.0240^{\mathrm{a}}-2.5033^{\mathrm{b}}$ \\
\hline
\end{tabular}




\begin{tabular}{|c|c|c|c|}
\hline Parametre & Normal & t-Student & GED \\
\hline \multicolumn{4}{|c|}{ AR(3,2)-EGARCH(1,0,1) } \\
\hline$\omega$ & $-1.3186^{c}$ & $-1.1606^{c}$ & -1.2083 \\
\hline$\alpha$ & $-0.1426^{c}$ & $-0.1463^{c}$ & $-0.1401^{c}$ \\
\hline$\theta$ & $0.7962^{a}$ & $0.8207^{a}$ & $0.8136^{a}$ \\
\hline LOGL & 721.5726 & 726.5455 & 728.151 \\
\hline $\mathrm{JB}$ & $17.68557^{a}$ & $33.05645^{a}$ & $32.47837^{a}$ \\
\hline $\operatorname{LB}^{2}(1)-A R C H(1)$ & $0.7940-0.7847$ & $0.4751-0.4692$ & $0.2830-0.2793$ \\
\hline LB $^{2}(5)-A R C H(5)$ & $7.7549-1.3532$ & $7.4902-1.3696$ & $6.4771-1.189$ \\
\hline LB $^{2}(10)-A R C H(10)$ & $44.2930^{\mathrm{a}}-3.4283^{\mathrm{a}}$ & $42.4330^{\mathrm{a}}-3.4230^{\mathrm{a}}$ & $37.3200^{\mathrm{a}}-3.0754^{\mathrm{a}}$ \\
\hline LB $^{2}(15)-A R C H(15)$ & $50.9110^{\mathrm{a}}-2.3887^{\mathrm{b}}$ & $48.4280^{\mathrm{a}}-2.4906^{\mathrm{b}}$ & $43.5310^{\mathrm{a}}-2.2870^{\mathrm{b}}$ \\
\hline \multicolumn{4}{|c|}{$\operatorname{AR}(3,2)-G A R C H(0,1)$} \\
\hline$\omega$ & $0.0015^{\mathrm{a}}$ & $0.0014^{a}$ & $0.0013^{a}$ \\
\hline$\beta$ & $0.1466^{c}$ & $0.2149^{c}$ & $0.1896^{c}$ \\
\hline LOGL & 706.229 & 723.9715 & 725.5392 \\
\hline JB & $27.77742^{a}$ & $33.36985^{a}$ & $34.04847^{a}$ \\
\hline LB$^{2}(1)-A R C H(1)$ & $0.1574-0.1555$ & $0.3567-0.3522$ & $0.2137-0.2109$ \\
\hline LB $^{2}(5)-A R C H(5)$ & $13.4860^{c}-2.6981^{c}$ & $11.3050^{\mathrm{c}}-2.3823^{\mathrm{c}}$ & $11.8000^{c}-2.4599^{c}$ \\
\hline LB $^{2}(10)-A R C H(10)$ & $44.5460^{a}-3.6273^{a}$ & $36.3550^{\mathrm{a}}-3.0080^{\mathrm{b}}$ & $37.4960^{\mathrm{a}}-3.0577^{\mathrm{b}}$ \\
\hline $\mathrm{LB}^{2}(15)-\mathrm{ARCH}(15)$ & $47.7320^{\mathrm{a}}-2.1807^{\mathrm{b}}$ & $37.6230^{b}-2.1429^{b}$ & $38.8130^{\mathrm{b}}-2.1864^{\mathrm{b}}$ \\
\hline \multicolumn{4}{|c|}{ AR(3,2)-EGARCH(0,1,1) } \\
\hline$\omega$ & $-6.6586^{a}$ & $-6.6774^{a}$ & $-6.6265^{a}$ \\
\hline$\beta$ & $0.3516^{b}$ & $0.3585^{c}$ & $0.2541^{\mathrm{c}}$ \\
\hline$\theta$ & -0.0847 & -0.0086 & -0.0635 \\
\hline LOGL & 705.6471 & 723.7282 & 724.5705 \\
\hline JB & $19.17342^{\mathrm{a}}$ & $23.64999^{a}$ & $24.69366^{\mathrm{a}}$ \\
\hline LB $^{2}(1)-A R C H(1)$ & $0.0004-0.0004$ & $0.0700-0.0691$ & $0.0126-0.0124$ \\
\hline LB $^{2}(5)-A R C H(5)$ & $16.0530^{\mathrm{b}}-3.1827^{\mathrm{b}}$ & $13.4210^{\mathrm{c}}-2.6517^{\mathrm{c}}$ & $12.4530^{\mathrm{c}}-2.3781^{\mathrm{c}}$ \\
\hline $\mathrm{LB}^{2}(10)-\mathrm{ARCH}(10)$ & $40.4480^{\mathrm{a}}-3.4559^{\mathrm{a}}$ & $39.0600^{\mathrm{a}}-3.0478^{\mathrm{b}}$ & $37.2610^{\mathrm{a}}-2.8667^{\mathrm{b}}$ \\
\hline $\mathrm{LB}^{2}(15)-\mathrm{ARCH}(15)$ & $44.6840^{\mathrm{a}}-2.4282^{\mathrm{b}}$ & $40.1100^{\mathrm{a}}-2.1713^{\mathrm{b}}$ & $38.5790^{\mathrm{b}}-2.0283^{\mathrm{c}}$ \\
\hline \multicolumn{4}{|c|}{$\operatorname{AR}(3,2)-G A R C H(1,1)$} \\
\hline$\omega$ & 0.0000 & 0.0000 & 0.0000 \\
\hline$\alpha$ & $0.0924^{a}$ & $0.0670^{\mathrm{b}}$ & $0.0789^{b}$ \\
\hline$\beta$ & $0.8976^{a}$ & $0.9278^{a}$ & $0.9120^{\mathrm{a}}$ \\
\hline LOGL & 727.3497 & 732.7207 & 732.5637 \\
\hline JB & $33.95651^{a}$ & $43.31290^{\mathrm{a}}$ & $39.33112^{\mathrm{a}}$ \\
\hline LB $^{2}(1)-A R C H(1)$ & $1.8768-1.8594$ & $2.0927-2.0733$ & $1.7300-1.7132$ \\
\hline LB $^{2}(5)-A R C H(5)$ & $8.0303-1.6269$ & $7.5658-1.4876$ & $8.0744-1.6692$ \\
\hline $\mathrm{LB}^{2}(10)-\mathrm{ARCH}(10)$ & $15.8780-1.5001$ & $20.4010^{\mathrm{c}}-1.9514^{\mathrm{c}}$ & $17.5820^{c}-1.6592^{c}$ \\
\hline LB $^{2}(15)-A R C H(15)$ & $16.9770-1.0484$ & $21.4000-1.3330$ & $18.5510-1.1476$ \\
\hline \multicolumn{4}{|c|}{$\operatorname{AR}(3,2)-\operatorname{EGARCH}(1,1,1)$} \\
\hline$\omega$ & $-0.2823^{b}$ & $-0.2930^{c}$ & -0.1646 \\
\hline$\alpha$ & $0.1628^{a}$ & $0.1757^{b}$ & $0.1211^{c}$ \\
\hline$\beta$ & $-0.0576^{a}$ & $-0.0660^{c}$ & $-0.0576^{b}$ \\
\hline$\theta$ & $0.9758^{a}$ & $0.9758^{a}$ & $0.9891^{\mathrm{a}}$ \\
\hline LOGL & 729.2521 & 741.0352 & 734.8165 \\
\hline JB & $48.77922^{\mathrm{a}}$ & $44.61156^{a}$ & $73.15259^{\mathrm{a}}$ \\
\hline LB $^{2}(1)-A R C H(1)$ & $2.2792-2.2592$ & $1.1534-1.1411$ & $1.5246-1.5084$ \\
\hline LB $^{2}(5)-A R C H(5)$ & $4.6940-0.9104$ & $4.9329-0.9735$ & $4.2952-0.8783$ \\
\hline $\mathrm{LB}^{2}(10)-\mathrm{ARCH}(10)$ & $25.3610^{\mathrm{b}}-2.6006^{\mathrm{b}}$ & $28.5980^{b}-2.5777^{b}$ & $23.5910^{\mathrm{b}}-2.3727^{\mathrm{b}}$ \\
\hline LB $^{2}(15)-A R C H(15)$ & $26.9930^{c}-1.6785^{c}$ & $31.4050^{b}-1.6403^{c}$ & $24.8720^{c}-1.5808^{c}$ \\
\hline
\end{tabular}

Döviz için verilen modeller incelendiğinde max. LOGL değeri için en iyi model t-student dağılımına göre $\operatorname{AR}(2,2)-\operatorname{EGARCH}(1,1,1)$ modelidir (Tablo 9). Asimetrik etki parametresinin $(\theta)$ döviz getiri serisi için pozitif ve istatistikî olarak \%1 düzeyinde anlamlı olduğu görülmektedir. Bu 
durum döviz getirileri için kötü haberin iyi habere göre döviz getiri oynaklığını daha fazla arttırdığını ifade etmektedir. Ayrıca, modellerden elde edilen standardize edilmiş hata terimlerinin karelerine ilişkin $\mathrm{LB}^{2}$ istatistikleri de hata terimleri arasında değişen varyans sorunu olmadığını ve $A R C H$ etkisinin kalmadığını da göstermektedir.

Tablo 9: Döviz için ARCH-GARCH-EGARCH Modelleri

\begin{tabular}{|c|c|c|c|}
\hline Parametre & Normal & t-Student & GED \\
\hline \multicolumn{4}{|c|}{$\operatorname{AR}(2,2)-\operatorname{ARCH}(1,0)$} \\
\hline$\omega$ & $0.0004^{c}$ & 0.0003 & $0.0004^{\mathrm{a}}$ \\
\hline$\alpha$ & -0.8168 & -0.2981 & $-0.8892^{c}$ \\
\hline LOGL & 1143.2662 & 1154.1491 & 1153.5441 \\
\hline JB & $27.4684^{a}$ & $32.9290^{a}$ & $34.1177^{a}$ \\
\hline $\mathrm{LB}^{2}(1)-A R C H(1)$ & $1.7912-1.7783$ & $0.6823-0.6759$ & $0.6610-0.6548$ \\
\hline $\mathrm{LB}^{2}(5)-\mathrm{ARCH}(5)$ & $8.5193-1.5390$ & $7.1019-1.3419$ & $7.3603-1.3982$ \\
\hline LB $^{2}(10)-A R C H(10)$ & $10.6760-1.0036$ & $8.3902-0.7988$ & $8.5910-0.8079$ \\
\hline LB $^{2}(15)-A R C H(15)$ & 17.9190-1.1191 & $15.7650-1.0208$ & $15.5520-0.9994$ \\
\hline \multicolumn{4}{|c|}{$\operatorname{AR}(2,2)-\operatorname{EGARCH}(1,0,1)$} \\
\hline$\omega$ & -11.5959 & 0.0209 & -13.1155 \\
\hline$\alpha$ & 0.0376 & $0.0453^{a}$ & 0.0326 \\
\hline$\theta$ & -0.3867 & $1.0025^{\mathrm{a}}$ & -0.5639 \\
\hline LOGL & 1143.3535 & 1160.1001 & 1153.5937 \\
\hline JB & $26.5188^{a}$ & $9.5768^{c}$ & $32.2520^{\mathrm{a}}$ \\
\hline $\mathrm{LB}^{2}(1)-\mathrm{ARCH}(1)$ & $1.7381-1.7250$ & $0.8578-0.8480$ & $0.6133-0.6074$ \\
\hline $\mathrm{LB}^{2}(5)-A R C H(5)$ & $8.7368-1.5938$ & $6.8708-1.2531$ & $6.9232-1.3105$ \\
\hline $\mathrm{LB}^{2}(10)-\mathrm{ARCH}(10)$ & $11.1150-1.0541$ & $10.3490-1.0417$ & $8.1477-0.7687$ \\
\hline LB $^{2}(15)-A R C H(15)$ & $18.2280-1.1427$ & $14.5130-1.1024$ & $14.9880-0.9648$ \\
\hline \multicolumn{4}{|c|}{$\operatorname{AR}(2,2)-G A R C H(0,1)$} \\
\hline$\omega$ & $0.0002^{\mathrm{a}}$ & $0.0002^{\mathrm{a}}$ & $0.0002^{a}$ \\
\hline$\beta$ & 0.0815 & 0.1229 & 0.1151 \\
\hline LOGL & 1144.4659 & 1155.6815 & 1150.012 \\
\hline JB & $37.6125^{a}$ & $45.7704^{a}$ & $42.8147^{a}$ \\
\hline $\mathrm{LB}^{2}(1)-\mathrm{ARCH}(1)$ & $0.0186-0.0183$ & $0.4317-0.4263$ & $0.2667-0.2634$ \\
\hline $\mathrm{LB}^{2}(5)-\mathrm{ARCH}(5)$ & 5.0891-1.0633 & $6.0587-1.2254$ & $4.9155-1.0629$ \\
\hline $\mathrm{LB}^{2}(10)-\mathrm{ARCH}(10)$ & $7.5146-0.7975$ & $7.5248-0.7562$ & $7.5749-0.8264$ \\
\hline LB $^{2}(15)-A R C H(15)$ & $14.2770-0.9701$ & $13.8160-0.9554$ & $14.1970-0.9868$ \\
\hline \multicolumn{4}{|c|}{$\operatorname{AR}(2,2)-\operatorname{EGARCH}(0,1,1)$} \\
\hline$\omega$ & $-8.4586^{a}$ & $-8.5627^{a}$ & $-8.5015^{a}$ \\
\hline$\beta$ & 0.1227 & 0.2261 & 0.1769 \\
\hline$\theta$ & 0.0412 & -0.0018 & 0.0196 \\
\hline LOGL & 1144.0983 & 1155.7969 & 1149.4992 \\
\hline JB & $35.2048^{\mathrm{a}}$ & $52.4381^{a}$ & $42.3106^{a}$ \\
\hline $\mathrm{LB}^{2}(1)-\mathrm{ARCH}(1)$ & $0.0816-0.0806$ & $0.2712-0.2679$ & $0.0154-0.0152$ \\
\hline $\mathrm{LB}^{2}(5)-\mathrm{ARCH}(5)$ & 5.4734-1.0906 & $5.2019-1.0451$ & $4.7263-0.9901$ \\
\hline LB $^{2}(10)-A R C H(10)$ & $8.0696-0.8211$ & $6.7773-0.6713$ & $7.4828-0.7910$ \\
\hline LB $^{2}(15)-A R C H(15)$ & $14.8680-0.9829$ & $12.7530-0.8669$ & $14.0640-0.9501$ \\
\hline \multicolumn{4}{|c|}{$\operatorname{AR}(2,2)-G A R C H(1,1)$} \\
\hline$\omega$ & $0.0000^{c}$ & 0.0000 & 0.0000 \\
\hline$\alpha$ & $0.0737^{c}$ & $0.0858^{c}$ & $0.0811^{\mathrm{c}}$ \\
\hline$\beta$ & $0.8943^{a}$ & $0.8836^{\mathrm{a}}$ & $0.8895^{\mathrm{a}}$ \\
\hline LOGL & 1150.8351 & 1160.1851 & 1158.3699 \\
\hline JB & $42.3369^{a}$ & $42.9583^{a}$ & $43.6616^{a}$ \\
\hline $\mathrm{LB}^{2}(1)-\mathrm{ARCH}(1)$ & $0.0145-0.0143$ & $0.0985-0.0972$ & $0.0695-0.0686$ \\
\hline $\mathrm{LB}^{2}(5)-A R C H(5)$ & $1.7590-0.3175$ & $2.3398-0.4317$ & $2.3650-0.4320$ \\
\hline
\end{tabular}




\begin{tabular}{|c|c|c|c|}
\hline $\operatorname{LB}^{2}(10)-A R C H(10)$ & $4.9214-0.5090$ & $5.5689-0.5933$ & $5.3336-0.5633$ \\
\hline LB $^{2}(15)-A R C H(15)$ & $11.2580-0.8295$ & $12.6290-0.8817$ & $12.0800-0.8512$ \\
\hline \multicolumn{4}{|c|}{ AR(2,2)-EGARCH(1,1,1) } \\
\hline$\omega$ & $-0.2662^{c}$ & $-0.3380^{c}$ & $-11.8588^{b}$ \\
\hline$\alpha$ & $0.0752^{c}$ & $0.1104^{c}$ & 0.2029 \\
\hline $\boldsymbol{\beta}$ & $0.0932^{\mathrm{a}}$ & $0.0847^{b}$ & 0.0296 \\
\hline$\theta$ & $0.9753^{\mathrm{a}}$ & $0.9700^{\mathrm{a}}$ & -0.3948 \\
\hline LOGL & 1156.9566 & 1163.4638 & 1155.0522 \\
\hline JB & $26.2289^{a}$ & $32.9327^{a}$ & $46.3739^{a}$ \\
\hline LB $^{2}(1)-A R C H(1)$ & $0.0731-0.0722$ & $0.0298-0.0294$ & $0.1722-0.1701$ \\
\hline LB $^{2}(5)-A R C H(5)$ & $1.7297-0.3297$ & $2.0349-0.3769$ & $4.7934-0.9634$ \\
\hline LB $^{2}(10)-A R C H(10)$ & $6.6984-0.6951$ & $6.5472-0.6875$ & $6.2740-0.6295$ \\
\hline LB $^{2}(15)-A R C H(15)$ & $11.1830-0.8389$ & $12.1270-0.8525$ & $12.2670-0.8378$ \\
\hline
\end{tabular}

Her bir seri için uygun olan model belirlendikten sonra öngörü aşamasına geçilmiştir. Bu aşamada model tahmininde dışarıda bırakılan 11.25.2006 tarihinden sonraki beş hafta için öngörüler hesaplanmış ve performansları tablo 10 'da verilmiştir.

Tablo 10: Öngörü Performansları

\begin{tabular}{lccccc}
\hline & Model & RMSE & MAE & MAPE & THEIL \\
\hline Altın & $\mathrm{AR}(2,4)-\mathrm{GARCH}(1,1)$ & 20.55971 & 17.03496 & 1.479935 & 0.008875 \\
\hline Borsa & $\mathrm{AR}(2,2)-\mathrm{EGARCH}(1,1,1)$ & 2596.741 & 2170.666 & 2.765573 & 0.016754 \\
\hline Döviz & $\mathrm{AR}(2,2)-\mathrm{EGARCH}(1,1,1)$ & 0.109238 & 0.081837 & 2.252153 & 0.015360 \\
\hline
\end{tabular}

Performans sonuçlarına göre, altın fiyatları ortalama \%1,5 hata ile öngörülmüş ve theil eşitsizlik katsayısı 0'a oldukça yakın bir değer almıştır. Buna göre üç değişken arasından en başarılı öngörü sonuçları altın değişkenine aittir. Öngörü performansları açısından altın değişkenini sırasıyla döviz ve borsa değişkenleri takip etmektedir.

\section{Sonuç}

Yatırım araçlarında meydana gelen dalgalanmalar, bu yatırım araçlarının gelecek değerlerinin öngörülmesi ve oynaklığının modellenmesi açısından önemlidir. Yatırım araçlarının gelecek değerlerini tahmin ederken, genellikle geleneksel Box-Jenkins yönteminin kullanıldığı görülmektedir. Fakat daha öncede de ifade edildiği gibi, özellikle finansal zaman serilerinde ele alınan dönem itibariyle ortalamanın sabit olmasına karşın varyansın zaman içerisinde değişmesinden dolayı son yıllarda finansal serilerin koşullu varyansındaki zamana bağlı değişkenliği analiz etmek için ARCH modelleri de Box-Jenkins modelleri ile birlikte kullanılmaya başlanmıştır. Bununla birlikte standart GARCH modelleri iyi ve kötü haberin oynaklık üzerinde neden olabileceği asimetrik etkiyi dikkate almamaktadır. Bu nedenle asimetrik etkinin araştırılması amacıyla EGARCH modeli GARCH modelleri ile birlikte kullanılmaktadır.

Çalışmada BIST100, altın ve petrol fiyatları ile döviz kuru değişkenleri geleneksel zaman serileri yöntemi olan Box-Jenkins ve $\mathrm{ARCH}$ modelleri ile öngörülmüştür. Bu amaçla öncelikle çalışmada kullanılan değişkenlerin tanımlayıcı istatistikleri belirlenmiştir. Sonrasında ele alınan değişkenlerin durağanlık seviyeleri tespit edildikten sonra uygun ARIMA modelleri ve ARCH modelleri ile öngörüde bulunulmuştur. Elde edilen bulgular değerlendirildiğinde, en yüksek getirinin borsa değişkenine ait olduğu görülmektedir. Bu durum, küresel finansal krizin Türkiye'deki etkisinin ele alınan dönem itibariyle ortadan kalkmaya başladığının bir göstergesi olarak yorumlanabilir. En düşük getirinin ise petrol değişkenine ait olduğu belirlenmiştir. Bu durum ise 2014 Haziran ayı itibariyle küresel petrol piyasasındaki arz fazlasının ortaya çıkması ile petrol fiyatlarındaki hızlı düşüşün bir sonucu olarak değerlendirilebilir. Ayrıca petrol değişkeninin ele alınan 
dönem boyunca diğer değişkenlere kıyasla daha oynak bir yapı sergilediği ortaya koyulmuştur. Son yıllarda Ortadoğu'da yaşanan siyasal krizler göz önüne alındığında petrolün yatırımcı açısından yüksek riske sahip bir yatırım aracı olduğu söylenebilir.

Ele alınan değişkenler için kurulan tüm ARIMA modellerinde ARCH etkisinin olduğu tespit edilmiştir. Bu durum literatürdeki, finansal verilerde koşullu varyansın zamana bağlı olarak değiştiği varsayımını desteklemektedir. Altın ve döviz fiyatları ile borsa endeksi için oluşturulan ARIMA modellerindeki değişen varyans probleminin $\mathrm{ARCH}$ modelleriyle giderildiği görülmüştür. Petrol fiyatlarının ele alındığı modelde ise ARCH etkisinin tamamen giderilemediği fakat nispeten azaldığı tespit edilmiştir. Bu doğrultuda ele alınan dönem itibariyle birçok ARIMA modelinin denenmesi ve $A R C H$ etkisinin ve değişen varyans sorununun ortadan kaldırılması ile birlikte GARCH modellerinin oluşturulması sonucunda, değişkenlere ait en uygun modeller belirlenmiştir.

Ayrıca altın fiyatları haricindeki tüm değişkenlerde asimetrik etkinin varlığı ortaya koyulmuştur. Döviz ve petrol için elde edilen modellerdeki asimetrik etki katsayısı anlamlı ve pozitiftir. Bu katsayıların pozitif olması fiyatlardaki yükselişlerin düşüşlere göre volatiliteyi daha fazla etkilediği anlamına gelmektedir. Bu durum, bu iki değişkendeki yükselişlerin piyasalarda olumsuz haber olarak algılanacağı düşünüldüğünde, literatürdeki olumsuz haberlerin olumlu haberlere göre daha fazla oynaklığa sebep olacağı varsayımına uymaktadır. Benzer şekilde borsa endeksi için kurulan modeldeki asimetrik etki katsayısının da negatif ve anlamlı olması literatürü desteklemektedir. Bu sonuçlar Peters (2001), Liu ve Hung (2010), Gökbulut vd. (2011), Abdalla (2012), Thorlie vd. (2014), Gökbulut ve Pekkaya (2014), Altuntaş ve Çolak (2015), Kandora ve Hamdi (2016), Büberkökü ve Kızıldere (2017)'nin çalışmalarıyla da benzerlik göstermektedir.

Çalışmada son olarak ARCH modellerinden elde edilen öngörülerin theil istatistiklerinin sıfıra yeterince yakın olduğu görülmektedir. Dolayısıyla modellerden elde edilen öngörülerin başarılı olduğu ve seçilen modellerin ilgili değişkenlerin gelecek değer öngörüsü için kullanılabilir olduğu söylenebilir. 


\section{Kaynaklar}

Abdalla, Suliman Zakaria Suliman (2012), "Modelling Exchange Rate Volatility using GARCH Models: Empirical Evidence from Arab Countries", International Journal of Economics and Finance, Vol. 4, No.3: 216-229.

Aggarwal, Reena; Inclan, Carla; Leal, Ricardo (1999), "Volatility in Emerging Stock Markets", Journal of Financial and Quantitative Analysis,Vol. 34, No. 1: 33-55.

Akomolafe, K. J.; Danladi, Jonathan D. (2013), “Modeling And Forecasting Crude Oil Price: Implications For The Nigeria's 2013 Budget. Proposal", International Journal Of Science And Research, Vol. 2, No. 5: 445-448.

Asad, Ali; Ch, Muhammda Iqbal; Qamar, Sadia; Akhtar, Noureen; Mahmood, Tahir; Hyder, Mehvish; Jamshed, Muhammad Tariq ( 2016), "Forecasting Of Daily Gold Price By Using Box-Jenkins Methodology", International Journal of Asian Social Science, Vol. 6, No. 11: 614-624.

Aygören, Hakan; Sarıtaş, Hakan; Moralı, Tuncay (2012), “iMKB 100 Endeksinin YSA ve Newton Nümerik Arama Modelleri ile Tahmini, Uluslararası Alanya İşletme Fakültesi Dergisi, C. 4, S. 1: 73-88.

Bircan, Hüdaverdi; Karagöz, Yalçın (2003), "Box-Jenkins Modelleri ile Aylık Döviz Kuru Tahmini Üzerine Bir Uygulama”, Kocaeli Üniversitesi Sosyal Bilimler Enstitüsü Dergisi, S. 6: 49-62.

Black, Fama (1976), "Studies of Stock Price Volatility Changes", https://brainmass.com/file/285288/Black_75.pdf , (Erişim: 10.09.2015).

Bollerslev, Tim (1986), “Generalized Autoregressive Conditional Heteroscedasticity”, Journal of Econometrics, Vol. 31, No. 3: $307-327$.

Büberkökü, Önder; Kızıldere, Celal (2017), “BIST100 Endeksinin Volatilite Özelliklerinin İncelenmesi”, V. Anadolu International Conference in Economics, May 11-13, 2017, Eskişehir, Türkiye.

Çevik, Osman (2002), “iMKB Endeksinin Box-Jenkins Yöntemi ile Modellenmesi”, Afyon Kocatepe Üniversitesi iiBF Dergisi, C. 4, S. 1: 17-31.

Deveci, Duygu (2013), "Predicting Gold and Silver Spot Prices in Turkey”,Yayınlanmamış Yüksek Lisans Tezi, Ortadoğu Teknik Üniversitesi.

Dickey, A. David; Fuller, Wayne A. (1979), "Distribution of the Estimators for Autoregressive Time Series with A Unit Root", Journal of the American Statistical Association, Vol. 74, No. 366: 427-431.

Engle, Robert F. (1982), "Autoregressive Conditional Heteroscedasticity with Estimates of the Variance of United Kingdom Inflation”, Econometrica, Vol. 50, No. 4: 987-1007.

Erdoğan, Olcay; Göksu, Ali (2014), "Forecasting Euro and Turkish Lira Exchange Rates With Artificial Neural Networks (Ann)", International Journal of Academic Research in Accounting, Finance and Management Sciences, Vol. 4, No. 4: 307-316.

Etuk, Ette Harrison; Uchendu, Bartholomew; Udo, Ephraim Okon (2012), “Box-Jenkins Modelling Of Nigerian Stock Prices Data", Greener Journal Of Science Engineering And Technological Research, Vol. 2, No. 2: 32-38.

Fernandez, Viviana (2007), “Forecasting Commodity Prices By Classification Methods: The Cases Of Crude Oil Andnatural Gas Spot Prices", Banco Central De Chile Conference, July 272007.

Gökbulut, IIlker Rasim; Gümrah, Ümit; Köseoğlu Derindere, Sinem (2011), “Modelling the volatility in Istanbul Stock Exchange : Shifting from Box- Jenkins to ARCH type models", İstanbul Üniversitesi İşletme Fakültesi Dergisi, C. 40, S. 2: 251-266.

Gökbulut, İlker Rasim; Pekkaya, Mehmet (2014), "Estimating and Forecasting Volatility of Financial Markets Using Asymmetric GARCH Models: An Application on Turkish Financial Markets", International Journal of Economics and Finance, Vol. 6, No. 4: 23-35.

Gupta, Sanjeev; Kashyap, Sachin (2015), “Box Jenkins Approach To Forecast Exchange Rate in India”, Pijmr, Vol. 7, No. 2: 1-11.

Kadılar, Cem; Şimşek, Muammer; Aladağ, Çağdaş Hakan (2009), "Forecasting The Exchange Rate Series With ANN: The Case Of Turkey", İstanbul Üniversitesi İktisat Fakültesi Ekonometri ve İstatistik Dergisi, S. 9: 17-29.

Kandora, Abbas; Hasbalrasol Abbas; Hamdi, Ahmed Mohammed Abdullah (2016), "Modelling Exchange Rate Volatility Using Asymmetric GARCH Models (Case Study Sudan)”, Journal of Mathematics, Vol. 12, No. 2: 71-77.

Kaynar, Oğuz; Taştan, Serkan; Demirkoparan, Ferhan (2010), " Ham Petrol Fiyatlarının YSA ile Tahmini”, Ege Akademik Bakış, C. 10, S. 2: 559-573. 


\section{Eskişehir Osmangazi Üniversitesi Iïß Dergisi}

Keskin Benli, Yasemin; Yıldız, Ayşe (2014), “Altın Fiyatının Zaman Serisi Yöntemleri ve YSA ile Öngörüsü”, Dumlupınar Üniversitesi Sosyal Bilimler Dergisi, S. 42: 213-224.

Khaemasunun,Pravit (2009), “Forecasting Thai Gold Prices. Available From Http://Www.Wbiconpro.Com/3-Pravit-.Pdf. (10.11.2016).

Khan, M. Massarrat Ali (2013), "Forecasting Of Gold Prices (Box Jenkins Approach)", International Journal of Emerging Technology and Advanced Engineering , Vol. 3, No. 3: 662-670.

Lineesh, M.C.; Minu, K.K.; John, C.Jessy (2010), “Analysis Of Non Stationary Nonlinear Economic Time Series Of Gold Price A Comprative Study", International Mathematical Forum, Vol 5, No. 34: 1673-1683.

Liu, Hung Chun; Hung, Jui Cheng (2010), "Forecasting S\&P-100 stock index volatility: The role of volatility asymmetry and distributional assumption in GARCH models", Expert Systems with Applications, Vol. 37, No. 7: 4928-4934.

Mensah, Emmanuel Kwasi (2015), "Box-Jenkins Modelling and Forecasting of Brent Crude Oil Price", Https://Mpra.Ub.Uni-Muenchen.De/67748/14/Mpra_Paper_67748.Pdf, (10.11.2016).

Muibi, Saibu Olufemi (2015), "Determining Optimal Crude Oil Price Benchmark in Nigeria: An Empirical Approach", The Romanian Economic Journal, Vol. 18, No. 58: 51-80.

Nelson, Daniel B. (1991), “Conditional Heteroscedasticity in Asset Returns: A New Approach”, Econometrica, Vol. 59, No. 2: 703-708.

Özalp, Alperen; Anagün, A. Sermet (2001), "Sektörel Hisse Senedi Fiyat Tahmininde Yapay Sinir Ağı Yaklaşımı ve Klasik Tahminleme Yöntemleri ile Karşılaştırılması”, Endüstri Mühendisliği Dergisi, C. 12, No. 3-4: 2-17.

Pacelli, Vincenzo (2012), "Forecasting Exchange Rates: A Comparative Analysis", International Journal of Business and Social Science, Vol. 3, No. 10: 145-156.

Peters, Jean Philippe (2001), "Estimating and forecasting volatility of stock indices using asymmetric GARCH models and (Skewed) Student-t densities", http://www.unalmed.edu.co/ ndgirald/Archivos\%20 Lectura/Archivos\%20curso\%20Series\%20II/jppeters.pdf (Erişim:13.06.2017).

Phillips, Peter; Perron, Pierre (1988), "Testing for a Unit Root in Time Series Regressions", Biometrika, Vol. 75, No. 2: 335-346.

Ping, Pung Yean; Miswan, Nor Hamizah; Ahmad, Maizah Hura (2013), "Forecasting Malaysian Gold Using Garch Model", Applied Mathematical Sciences, Vol. 7, No. 58: 2879 - 2884.

Sekreter, Ahmet; Gürsoy, Faruk (2014), “Combining Forecasting Method vs. Individual Forecasting Methods: Evidence from Istanbul Stock Exchange National 100 Index", The Empirical Economics Letters, Vol. 13, No. 7: 735-743.

Tambi, Mahesh Kumar (2005), "Forecastıng Exchange Rate A Uni-Variate Out of Sample Approach (Box-Jenkins Methodology)", The lup Journal of Bank Management, Vol. 4, No. 2: 60-74.

Taşpunar Altuntaş, Semra; Çolak, Fatma Deniz (2015), "BiST-100 Endeksinde Volatilitenin Modellenmesi Ve Öngörülmesinde ARCH Modelleri”, İstanbul Üniversitesi İşletme İktisadı Enstitüsü Dergisi, S. 79: 208-223.

Tayyar, Nezih; Tekin, Selin (2013), “ iMKB-100 Endeksinin Destek Vektör Makineleri İle Günlük, Haftalık ve Aylık Veriler Kullanarak Tahmin Edilmesi “,AiBÜ Sosyal Bilimler Enstitüsü Dergisi, C. 13, S. 1: 189-217.

Thorlie, Milton Abdul; Song, Lixin; Wang, Xiaoguang; Amin, Muhammad (2014), "Modelling Exchange Rate Volatility Using Asymmetric GARCH Models (Evidence from Sierra Leone)", International Journal of Science and Research, Vol. 3, No. 11: 1206-1214.

Tlegenova, Daniya (2015), "Forecasting Exchange Rates Using Time Series Analysis: The Sample Of The Currency Of Kazakistan”, Https://Arxiv.Org/Ftp/Arxiv/Papers/1508/1508.07534.Pdf, (Erişim: 21.11.2016).

Xie, Wen; Yu, Lean; Shanying, Xu; Wang, Shouyang (2006), "A New Method For Crude Oil Price Forecasting Based On Support Vector Machines", International Conference on Computational Science, 444-451.

Yayar, Rüştü; Karaca, Serdar (2011), "Estimating Index and an Aplication on the Istanbul Stock Exchange (Ise) Natıionalindustrials Index", Muhasebe Bilim Dünyası Dergisi, C. 13, S. 2: 164-188.

Yaziz, Siti Roslindar; Ahmad, Maizah Hura; Nian, Lee Chee; Muhammad, Noryanti (2011), “A Comparative Study on Box-Jenkins and Garch Models in Forecasting Crude Oil Prices", Journal of Applied Sciences, Vol. 11, No. 7: 11291135 . 


\section{Ek1: ARIMA model seçimi için eviews kodu}

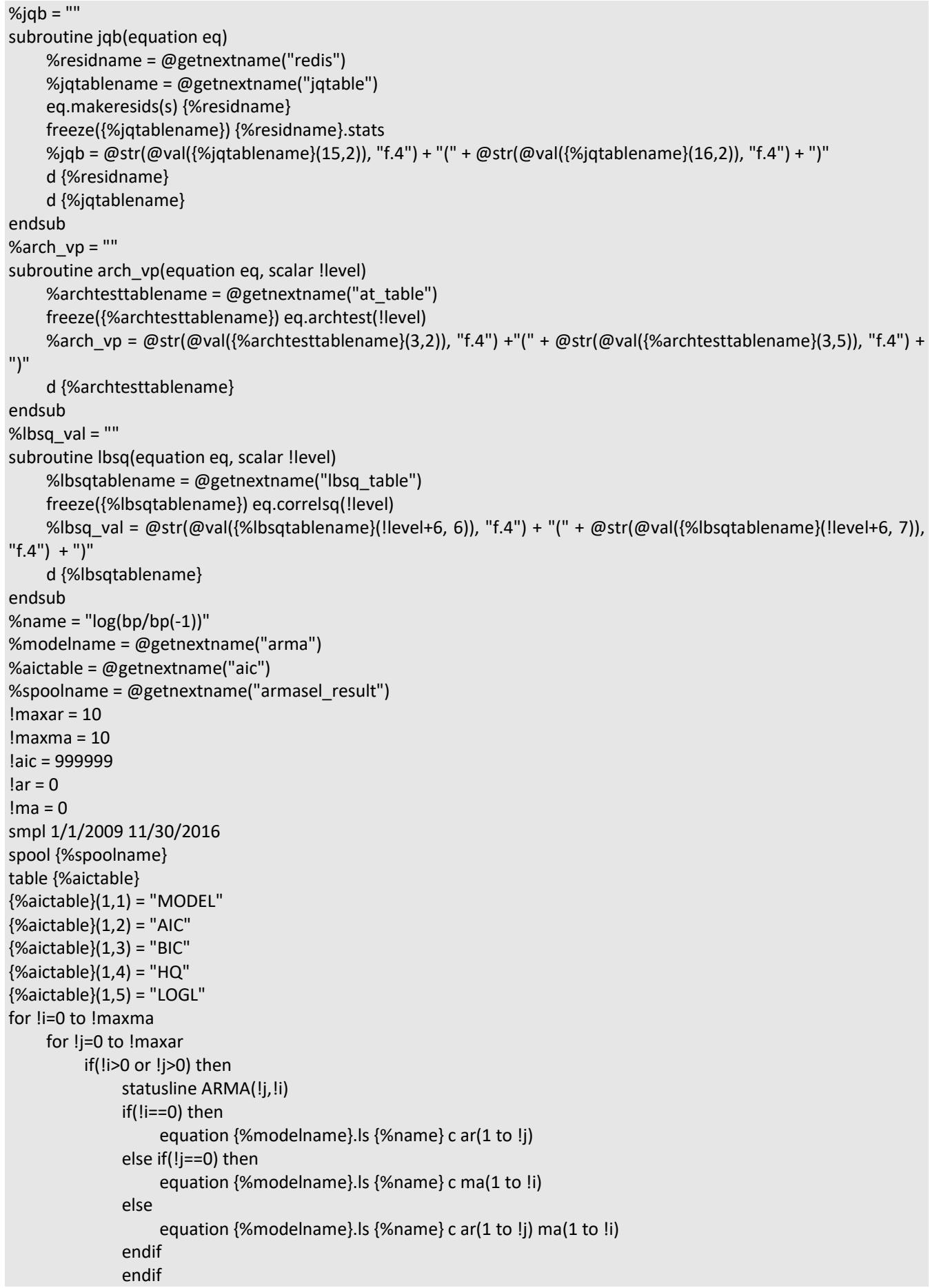




\section{Eskişehir Osmangazi Üniversitesi IïBF Dergisi}

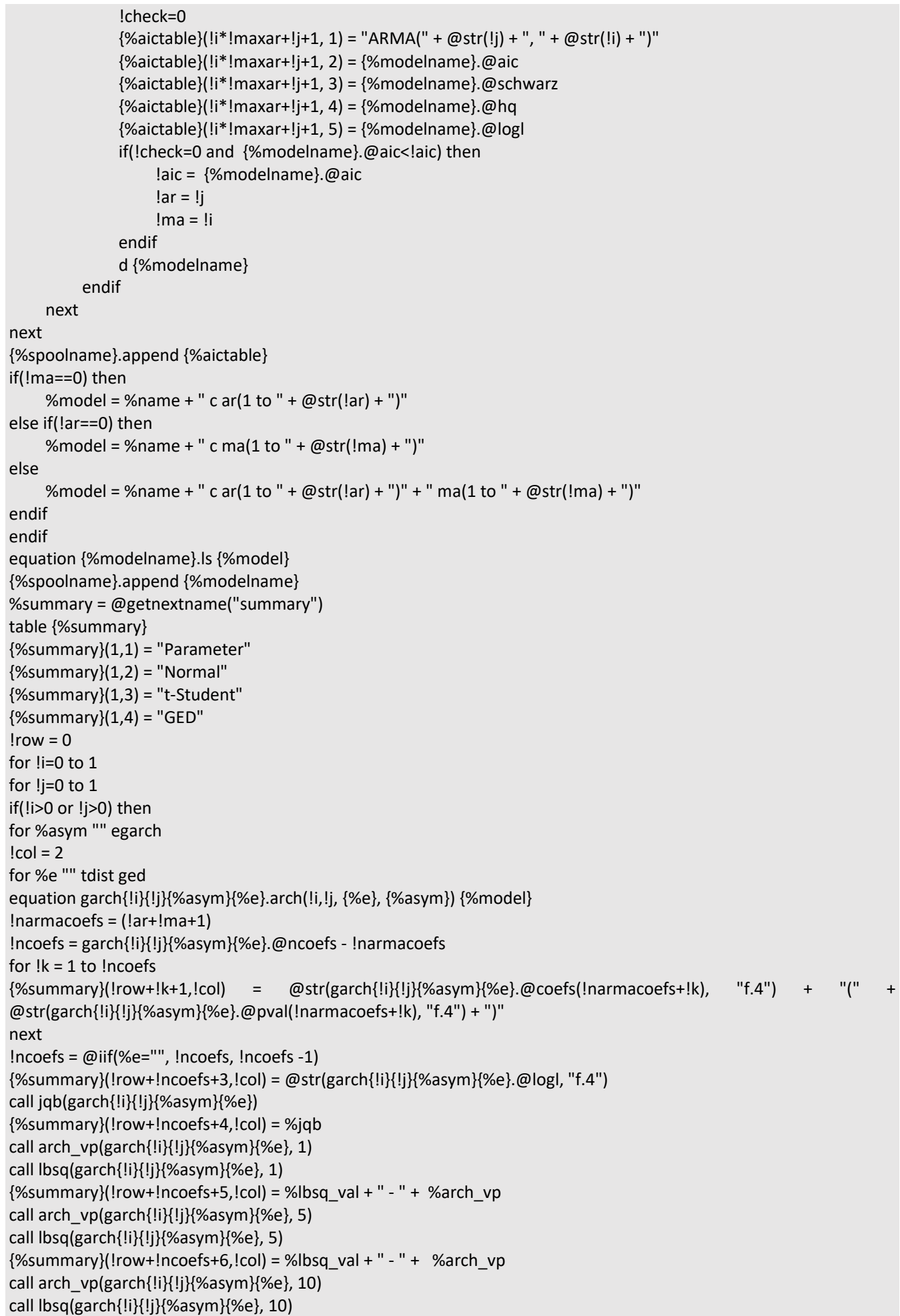




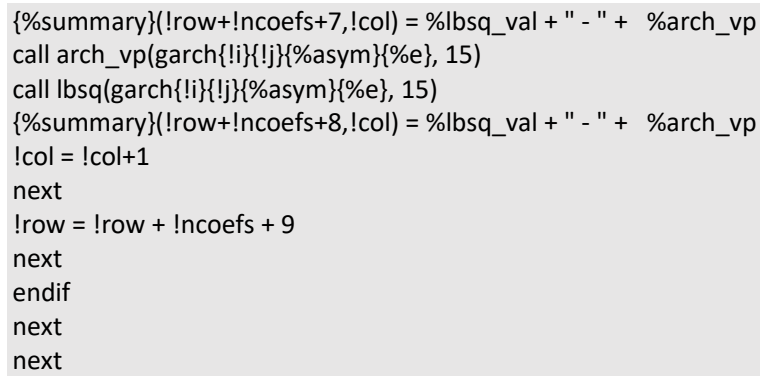

\section{Ek2: ARCH modelleri için geliştirilen Eviews program kodu}

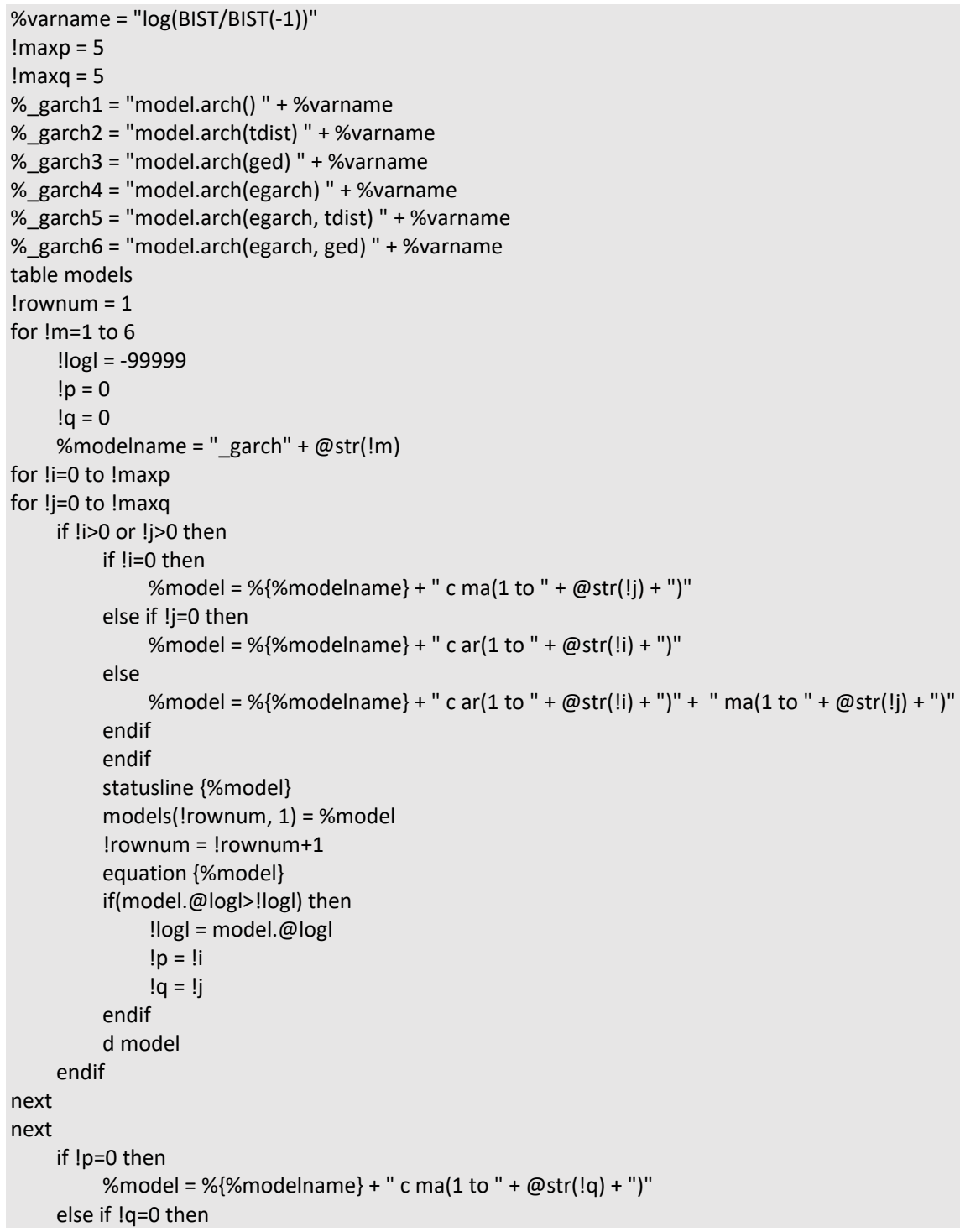


Eskişehir Osmangazi Üniversitesi ïBF Dergisi

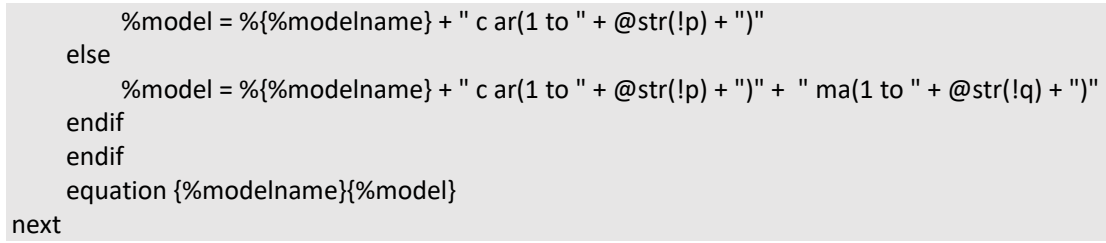

